\title{
Low molecular weight, non-peptidic agonists of TrkA receptor with NGF-mimetic activity
}

\author{
This article has been corrected since Online Publication and a corrigendum has also been published
}

\author{
D Scarpi ${ }^{1,8}$, D Cirelli ${ }^{2,8}$, C Matrone ${ }^{3}$, G Castronovo ${ }^{2}$, P Rosini ${ }^{2}$, EG Occhiato ${ }^{1}, \mathrm{~F}$ Romano ${ }^{2}$, L Bartali ${ }^{1}$, AM Clemente ${ }^{2}$, G Bottegoni ${ }^{4}$, \\ A Cavalli ${ }^{4}$, G De Chiara ${ }^{5}$, P Bonini ${ }^{2}$, P Calissano ${ }^{3}$, AT Palamara ${ }^{6}$, E Garaci ${ }^{7}$, MG Torcia ${ }^{2}$, A Guarna ${ }^{1,9}$ and F Cozzolino*,2,9
}

Exploitation of the biologic activity of neurotrophins is desirable for medical purposes, but their protein nature intrinsically bears adverse pharmacokinetic properties. Here, we report synthesis and biologic characterization of a novel class of low molecular weight, non-peptidic compounds with NGF (nerve growth factor)-mimetic properties. MT2, a representative compound, bound to Trk (tropomyosin kinase receptor)A chain on NGF-sensitive cells, as well as in cell-free assays, at nanomolar concentrations and induced TrkA autophosphorylation and receptor-mediated internalization. MT2 binding involved at least two amino-acid residues within TrkA molecule. Like NGF, MT2 increased phosphorylation of extracellular signal-regulated kinase1/2 and Akt proteins and production of MKP-1 phosphatase (dual specificity phosphatase 1), modulated p38 mitogen-activated protein kinase activation, sustained survival of serum-starved PC12 or RDG cells, and promoted their differentiation. However, the intensity of such responses was heterogenous, as the ability of maintaining survival was equally possessed by NGF and MT2, whereas the induction of differentiation was expressed at definitely lower levels by the mimetic. Analysis of TrkA autophosphorylation patterns induced by MT2 revealed a strong tyrosine (Tyr)490 and a limited Tyr785 and Tyr674/675 activation, findings coherent with the observed functional divarication. Consistently, in an NGF-deprived rat hippocampal neuronal model of Alzheimer Disease, MT2 could correct the biochemical abnormalities and sustain cell survival. Thus, NGF mimetics may reveal interesting investigational tools in neurobiology, as well as promising drug candidates.

Cell Death and Disease (2012) 3, e339; doi:10.1038/cddis.2012.80; published online 5 July 2012

Subject Category: Experimental Medicine

Neurotrophins are a family of cytokines that regulate proliferation, differentiation, and survival of neural cells, as well as a growing number of nonneural cell types. ${ }^{1,2}$ The molecular structures responsible for biologic signal transduction in responding cells are two classes of cell surface receptors. The low-affinity neurotrophin receptor p75 $\left(p 75^{\mathrm{NTR}}\right)$ binds all neurotrophins with similar affinity, whereas the high-affinity receptors, belonging to the superfamily of tropomyosin kinase receptor (Trk), bind each neurotrophin in a specific manner. ${ }^{1}$ When co-expressed, $\mathrm{p} 75^{\mathrm{NTR}}$ and TrkA receptors' may form an NGF (nerve growth factor) binding complex, ${ }^{3}$ although recent work indicates that the two molecules cooperate through convergence of downstream signaling pathways in generating the overall biologic effects. ${ }^{4}$ Activation of each Trk receptor is triggered by binding of the cognate neurotrophin at highly specific contact regions. The crystal structure of NGF in complex with human TrkA-d5 provided useful information on such regions, critical for biological activity, binding, and specificity. ${ }^{5}$ The subsequent response mainly originates from Trk receptors' autocatalytic activity, which results in the reciprocal phosphorylation of tyrosine (Tyr) residues within the intracytosolic tails of acceptor chains. Of the 11 tyrosine residues contained in the intracellular tail of TrkA (Uniprot, ID P04629), detailed information about the role of each of them is available for just a few $(\operatorname{six})^{6}$ a condition that hampered the complete understanding of how the biologic signal triggered by NGF is converted into the complex, ordered set of biochemical cascades that takes place in responding cells.

The overall signal imparted by neurotrophins through Trk receptors' catalytic activity is compounded by tropic, trophic, and differentiation-inducing responses that jointly ensure

\footnotetext{
${ }^{1}$ Department of Chemistry 'Ugo Schiff', University of Firenze, Via della Lastruccia 13, Sesto Fiorentino, I-50019 Firenze, Italy; ${ }^{2}$ Department of Clinical Physiopathology, University of Firenze, Viale Pieraccini 6, I-50139 Firenze, Italy; ${ }^{3}$ Nerve Growth Factor Laboratory, Institute of Neurobiology and Molecular Medicine and European Brain Research Institute-CERC Centro Europeo di Ricerca sul Cervello, Via del Fosso del Fiorano 64, I-00143 Roma, Italy; ${ }^{4}$ Department of Pharmaceutical Sciences, University of Bologna 'Alma Mater', Via Belmoro 6, Bologna I-40126, Italy; ${ }^{5}$ Department of Cell Biology and Neuroscience, ISS, Viale Regina Elena 299 , I-00166 Rome, Italy; ${ }^{6}$ Department of Public Health Sciences, University of Rome 'La Sapienza', Piazzale Aldo Moro 5, I-00185 Roma, Italy and ${ }^{7}$ Department of Experimental Medicine, University of Rome 'Tor Vergata', Via Montpellier 1, I-00133 Roma, Italy

*Corresponding author: F Cozzolino, Department of Clinical Physiopathology, University of Firenze, Viale Pieraccini 6, I-50139 Firenze, Italy. Tel: +39 55 4271 401 ; Fax: +39 55 4271 550; E-mail: federico.cozzolino@unifi.it

${ }^{8}$ These authors contributed equally to this work.

${ }^{9}$ These authors contributed equally to this work.

Keywords: nerve growth factor; TRK-A; peptidomimetics; MAP kinases; apoptosis

Abbreviations: NGF, nerve growth factor; Trk, tropomyosin kinase receptor; MTT, thiazolyl blue tetrazolium bromide; VGF, nerve growth factor inducible; DRG, dorsal root ganglia; WT, wild type; hr, human recombinant; ERK, extracellular signal-regulated kinase; JNK, c-Jun N-terminal kinases; MAPK, mitogen-activated protein kinase; MKP-1, dual specificity phosphatase 1; APP, amyloid precursor protein; PS1, presenilin 1; Tyr, tyrosine; ECD, extracellular domain

Received 27.10.11; revised 21.3.12; accepted 03.5.12; Edited by A Verkhratsky
} 
the structural and functional tuning of responding cells and tissues. $^{7}$ In this connection, it is not surprising that neurotrophins, and possibly compounds acting on their receptors, have been proposed as therapeutic tools in a number of disorders, ranging from neurodegenerative diseases, such as Alzheimer Disease or Parkinson Disease, to corneal neurotrophic ulcers, stroke, and cancer. ${ }^{8}$ Nevertheless, neurotrophins themselves share poor pharmacokinetic profiles, mainly because of their sensitivity to proteolysis, restricted penetration of the blood-brain barrier, and limited ability to diffuse in tissues, factors that all hamper their use as drugs. Therefore, small molecules able to interact with the NTRs, either as agonists or as antagonists, are of great interest for many therapeutic applications and could represent the suitable solution for the above pharmacokinetic drawbacks.

Peptidomimetic structures represent a useful tool in drug discovery, as modifications of bioactive peptides can result in better pharmacological properties, such as higher metabolic stability, increased bioavailability, and higher receptor affinity or selectivity. ${ }^{9}$ We therefore decided to obtain neurotrophin mimetics and focussed our interest on the interaction of NGF with TrkA receptor, considering the spatial coordinates of their interfaces. Thus, we conceived a chemical library based on a new class of peptidomimetics developed in our laboratories. ${ }^{10}$ An extensive biochemical and functional characterization revealed that some compounds within the library are endowed with NGF mimetic properties.

\section{Results}

Screening of the chemical library. Taking into account the spatial conformation of the binding site for NGF in TrkA, compounds with molecular dimensions fitting in the domain- 5 pouch ${ }^{5}$ were selected from a chemical library based on a bicyclic three-dimensional scaffold, prepared from commercial sources in which derivatives are differently decorated with the side chains of proteinogenic amino acids and are compatible with solid phase peptide synthesis. ${ }^{11,12}$ Over hundred fifty compounds were initially screened by selecting active molecules for the ability to sustain survival, assessed by the MTT(thiazolyl blue tetrazolium bromide) test, of PC12 cells cultured in the absence of serum, using rhNGF as

Figure 1 NGF mimetic activity of selected compounds. (a) PC12 cells were cultured for $72 \mathrm{~h}$ in serum-free medium in the presence or absence of the indicated concentrations of compounds $n .11(\bigcirc), 13(\triangle), 46(\nabla), 60(\diamond)$, or $4 \mathrm{nM}$ hrNGF as positive control. Cell survival was measured as MTT incorporation of triplicate cultures and expressed as percentage of the survival activity induced by hrNGF. Results of four different experiments (mean \pm S.E.) are reported. (b) Structural formula of the compounds n. 11, 13, 46, 60. Compound n. 11 was named MT2. (c) PC3 cells were cultured for $48 \mathrm{~h}$ in the presence or absence of the indicated concentrations of compounds n. $(\bigcirc), 13(\triangle), 46(\nabla), 60(\diamond)$ or $4 \mathrm{nM}$ hrNGF as positive control. Data are expressed as stimulation index $\left({ }^{3} \mathrm{H}-\mathrm{TdR}\right.$ incorporation in stimulated cultures $/{ }^{3} \mathrm{H}-\mathrm{TdR}$ incorporation in unstimulated cultures). Stimulation index obtained with $4 \mathrm{nM}$ of hrNGF was $2.3 \pm 0.18$ (mean \pm S.E.). Results of three different experiments (mean \pm S.E.) are reported. (d) Effect of MT2 on apoptosis induced by serum starvation. PC12 cells were cultured in serum-free medium in the presence or absence of different concentrations of MT2 or $4 \mathrm{nM}$ hrNGF as positive control. Cells were washed, stained with FITC Annexin V/PI and the percentage of Annexin ${ }^{+} \mathrm{PI}^{-}$cells recorded by cytofluorimetry. Statistical analysis, performed by Student's $t$-test shows significant differences $(P$ at least $<0.01)$ between untreated versus treated (any concentration) starved cultures

internal standard. A great variability existed in the performance of the active compounds, likely related to structural and spatial differences in the scaffold and its decoration. The structure of four compounds which repeatedly showed NGF-mimetic activity with a dose-dependent effect in this assay is shown in (Figures 1a and b; Supplementary Table 1

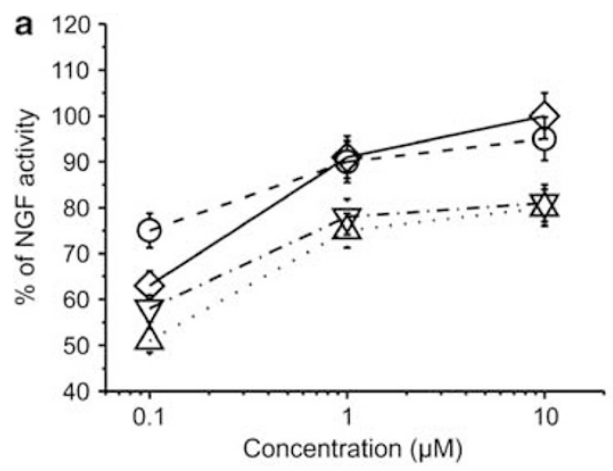<smiles>COC(=O)C1OC2OC1C(=O)N(Cc1ccccc1)C2Cc1ccccc1</smiles>

ก. 11<smiles>CC(=O)[C@H]1O[C@@H]2O[C@H]1CN(C(F)F)[C@H]2CO</smiles>

ก. 46

C
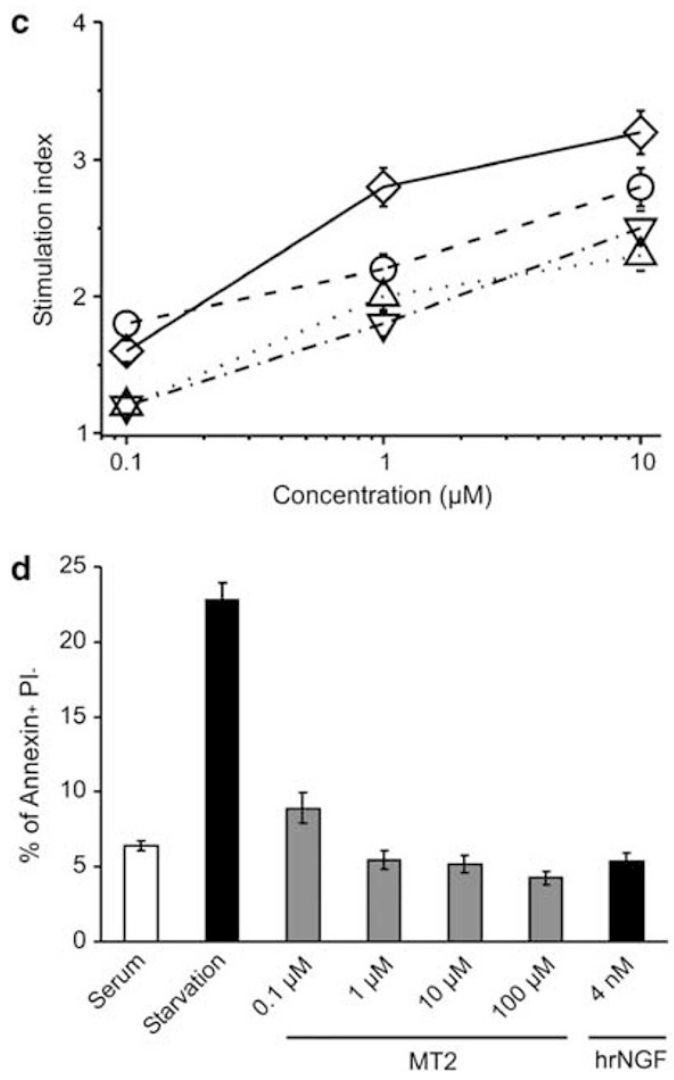
Chemical name of active compounds - Supplementary Information).

Next, as NGF promotes proliferation of the prostatic carcinoma cell line PC3, which does not express $p 75^{\mathrm{NTR}}$, we chose this assay to assess whether the active compounds selectively interact with TrkA, rather than $\mathrm{p} 75^{\mathrm{NTR}}$ or heterodimeric complex. Figure 1c reports the proliferation indexes induced by the four compounds, which were able to induce a vigorous growth, at times even stronger than that elicited by NGF. Thus, transmission of biologic signal presumably relied solely on their interaction with TrkA chain.

At the end of the selection procedure, we chose the molecules endowed with the highest NGF-like activity and addressed them to further studies. Henceforth, the functional analysis of one representative molecule, named MT2, will be reported. As serum deprivation typically triggers the intrinsic pathway of apoptosis, to explain the survival-promoting activity induced by NGF mimetics in serum-deprived PC12 cells, we wanted to study specifically whether the apoptotic process could be downregulated by MT2 and chose an early event to measure its activity, the surface exposure of phosphatidyl-serine in PC12. Figure 1d shows that the compound was able to markedly affect the apoptosis that takes place upon serum starvation, in a dosedependent fashion and at levels even higher than those attained by optimal concentrations of human recombinant (hr) NGF.

Interaction with TrkA receptor. Based on the above evidence of a selective interaction with TrkA, we set up initial binding studies with ${ }^{125}$ I-NGF on PC12 cells and tested cold MT2 for its ability to displace the binding of fixed amounts of iodinated cytokine. Figure $2 \mathrm{a}$ shows the results of a representative experiment, which indicated an affinity of MT2 for TrkA in the nanomolar range of concentration.

This analysis, albeit suggestive, could not demonstrate conclusively that the NGF mimetic compound actually bound to TrkA. We therefore transfected plasmids coding human fulllength TrkA chain into TrkA ${ }^{-}$NIH-3T3 cells and obtained stable transfectants. Such cells were then used in binding experiments with MT2, labeled by introducing a ${ }^{3} \mathrm{H}$-methyl moiety as the final step of the synthetic procedure. Analysis of binding data at $4^{\circ} \mathrm{C}$ revealed $K_{\mathrm{d}}$ values of the MT2/TrkA interaction ranging between 50 and $100 \mathrm{nM}$ (Figure 2b); no specific binding was evident on mock-transfected-NIH 3T3 cells (data not shown). As expected, cold recombinant human NGF efficiently displaced binding of the tritiated compound (Figure 2c). In further experiments, after incubation at $4^{\circ} \mathrm{C}$, reactants were brought at $37^{\circ} \mathrm{C}$ to observe ligand internalization, which indeed occurred in TrkA ${ }^{+} \mathrm{NIH}-3 \mathrm{~T} 3$ cells, but not in mock-transfected cells (Figure $2 \mathrm{~d}$ ); again, ${ }^{3} \mathrm{H}-\mathrm{MT} 2$ internalization was blocked by rhNGF. Consistently, no internalization of labeled MT2 was observed in human erythocytes (RBC) kept at $37^{\circ} \mathrm{C}$ for $1 \mathrm{~h}$ (Figure $2 \mathrm{~d}$ ).

We finally wanted to obtain direct, unequivocal evidence of MT2-TrkA interaction, performing cell-free binding experiments with labeled MT2 and the extracellular portion of the receptor chain expressed in recombinant form. Repeated experiments yielded results completely coherent with those provided by the cell-based approach, as the specific binding observed displayed superimposable affinity, with $K_{\mathrm{d}}$ values ranging between $\sim 20$ and $80 \mathrm{nM}$ (Figure $2 \mathrm{e}$ ).

Thus, MT2 molecule was able to bind TrkA in a specific manner, undergoing subsequent receptor-mediated internalization, antagonized by the native neurotrophin, and failed to passively diffuse through cellular membranes. The affinity of the reaction nicely correlated with the survival activity of the compound, which was therefore likely related to its interaction with TrkA receptor chain.

Molecular models and binding hypothesis. Domain- 5 of TrkA contains amino-acid residues directly involved in the contact between NGF and TrkA. ${ }^{8}$ Thus, we asked whether MT2 interacts with any of those TrkA residues and chose to conduct molecular modeling studies, in which docking was performed as a global energy optimization by means of the biased probability Monte Carlo stochastic procedure. ${ }^{13}$ It turned out that MT2 bound TrkA's fifth domain at a shallow hydrophobic cavity in the region close to the membrane. The pocket is present in both the subunits but only one monomer was in contact with the molecule. As shown in Figure 3, MT2 established three key interactions with the protein: (i) one of the benzyl moieties formed a $\pi$-stacking interaction with Phe327, almost completely overlapping to the side chain of NGF Arg103, (ii) the other benzyl ring formed hydrophobic interactions with the methyl group of Thr352 and with the side chain of Val354, fitting the region that in the co-crystal is occupied by lle31 of NGF, and (iii) the carbonyl oxygen of the methyl ester chain formed a hydrogen bond with Thr325. The evidence that the compound likely interacts with residues engaged by NGF indicates partly shared contact regions between the latter and its mimetics that may reveal functionally meaningful.

We therefore checked whether the interaction of NGF mimetics with TrkA involves the amino-acid residues predicted by the docking analysis reported above. We transfected NIH-3T3 cells with T352A or F327A mutants of the full-length TrkA-coding construct, selected stable transfectants, and used them to perform binding experiments with tritiated MT2, as described above. Consistent with the docking analysis, the results showed virtual absence of a saturation curve (data not shown), confirming that those residues were critical for MT2 binding to TrkA.

Induction of biochemical events in NGF-sensitive cells. The first demonstrable event upon NGF binding to TrkA is autophosphorylation of the receptor. ${ }^{1}$ To ascertain whether such event is induced by MT2, we prepared western blots, developed with anti-phosphotyrosine (PY) antibodies, of TrkA immunoprecipitates from PC12 cells exposed to NGF or MT2 (Figure 4a). It is evident that the compound was able to induce autophosphorylation, but at lower levels compared with NGF, a finding raising the question of whether a full-blown pattern of receptor activation is actually triggered by the NGF mimetic compound.

Upon exposure to the neurotrophin, NGF-sensitive cells express sets of genes that bring about the relevant cell typespecific response; in $\mathrm{PC} 12$ cells, one of the most reproducible event is expression of VGF gene, which is either de novo expressed or strongly upregulated by NGF signaling. ${ }^{14}$ 


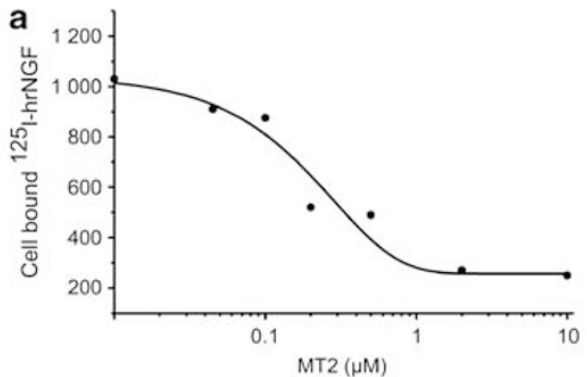

b
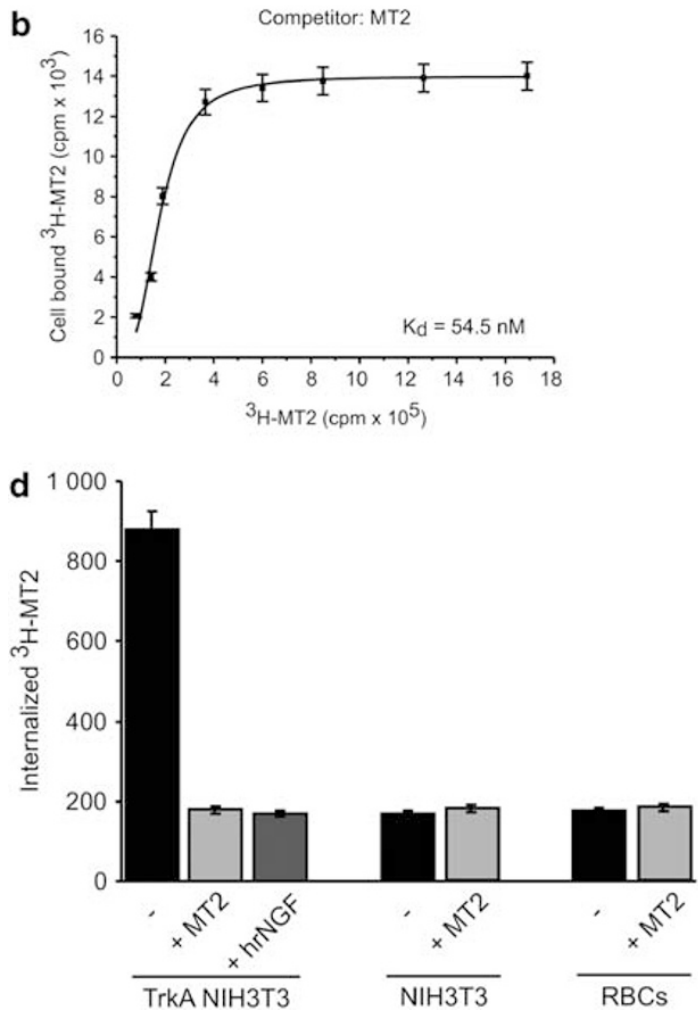

C

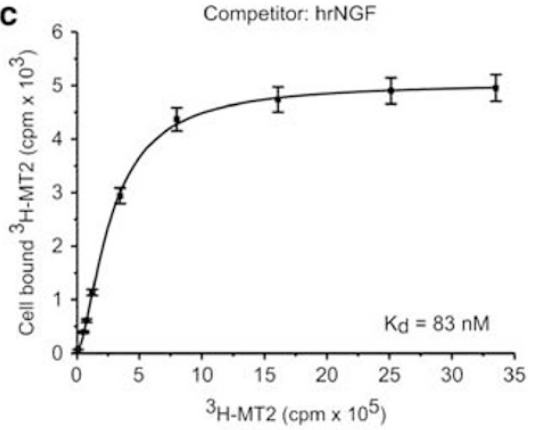

e

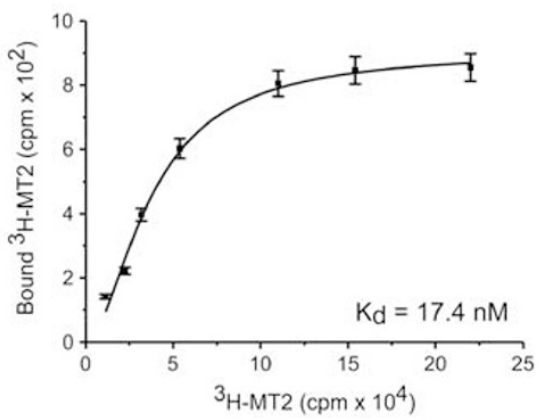

Figure 2 MT2 interactions with TrkA. (a) Displacement of ${ }^{125}$ I-hrNGF bound to PC12 cells by MT2. PC12 cells were incubated with 0.1 nM ${ }^{125}$-hrNGF in the presence or absence of different concentrations of MT2. Specific cell bound radioactivity was calculated and the results analyzed by Origin software. Results of one representative experiment out of three performed are shown. (b and c) Binding of ${ }^{3} \mathrm{H}-\mathrm{MT} 2$ to TrkA NIH-3T3. NIH-3T3, stably transfected with full-length human TrkA, were incubated in triplicate with different concentrations of ${ }^{3} \mathrm{H}-\mathrm{MT} 2$, in the presence or absence of excess cold MT2 (b) or $4 \mathrm{nM}$ cold hrNGF (c). Specific cell bound radioactivity was calculated and the results analyzed by the Origin software (one-site binding assay). No specific binding was recorded on mock-transfected NIH-3T3 cells (not shown). (d) Internalization of ${ }^{3} \mathrm{H}-\mathrm{MT2}$. TrkA-NIH-3T3 or mock-transfected cells were incubated for $1 \mathrm{~h}$ at $4^{\circ} \mathrm{C}$ with ${ }^{3} \mathrm{H}-\mathrm{MT} 2$ in the presence or absence of excess cold MT2 or hrNGF. Then, cells were washed and brought at $37^{\circ} \mathrm{C}$ for $1 \mathrm{~h}$. Membrane radioactivity was eluted with $0.1 \mathrm{M}$ glycine buffer, $\mathrm{pH} 2.8$. RBC were incubated for $1 \mathrm{~h}$ at $37^{\circ} \mathrm{C}$ with ${ }^{3} \mathrm{H}-\mathrm{MT} 2$ in the presence or absence of excess cold MT2 or hrNGF. Cells were lysed, and cell-bound radioactivity recorded. Data are expressed as mean bound radioactivity \pm S.E. of triplicate cultures. Results of one representative experiments out of three performed are shown. (e) MT2 interaction with the ECD fraction of human recombinant TrkA. One microgram purified TrkA ECD was incubated in triplicate with different concentrations of ${ }^{3} \mathrm{H}-\mathrm{MT} 2$, in the presence or absence of excess cold MT2. The mixture was absorbed on filter papers and, after washing, the radioactivity recorded. Data were analyzed by Origin software. Results from one representative experiments out of three performed are shown

Treatment of PC12 cells with MT2 clearly induced definite increases in the amount of VGF, albeit less pronounced than those elicited by NGF (Figure 4b). This finding indicates that significant differences may exist in the spectrum of signals generated by TrkA upon triggering by different ligands.

As the latter point was deemed critical for elucidating the functional properties of NGF mimetics, the compound was tested in another typical NGF-dependent assay: the induction of mitotic arrest and neurite outgrowth in $\mathrm{PC} 12$ cells. Figure 4c shows that MT2 treatment of PC12 cells for 3 days consistently induced morphology modifications, as cells tended to aggregate into clumps and to extend neuritic processes, that appeared, however, shorter and in limited numbers compared with NGF. Furthermore, while cultures exposed to NGF for 7 days reached an almost complete neurite-like morphology and aggregated to form small clumps, cells treated with MT2 appeared less differentiated and formed larger aggregates (Figure 4d). However, after 7 days, MT2 blocked cell growth at levels comparable with those sustained by saturating amounts of hrNGF (Figure 4e). Consistently, when embryonic dorsal root ganglia (DRG) cells were studied, MT2 induced an NGF-like neurite 


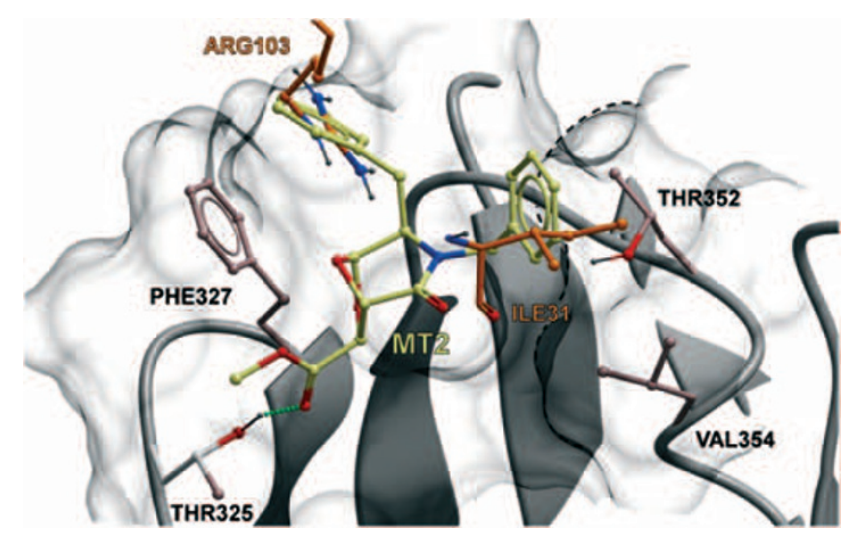

Figure 3 Binding sites of MT2 in TrkA molecule. In silico prediction of aminoacid residues involved. The predicted bound conformation of MT2 at the binding site of TrkA is shown. The surface of the pocket is reported explicitly with the structure of TrkA in gray ribbons as background. The amino acids of TrkA that establish direct interaction with MT2 are displayed in ball and stick representation. MT2 is displayed in ball and stick with carbon atoms colored dark yellow. As a term of comparison, Arg103 and lle31 of NGF are reported in ball and stick with the carbon atoms colored orange. The H-bond between Thr325 of TrkA and MT2 is highlighted with green dots. The van der Waals volume of part of Thr352 and Val354 side chains is highlighted with a black dotted line

growth-promoting activity after 4 days (Figures $4 \mathrm{f}-\mathrm{i}$ ); even if neuritic arborization and fasciculation appeared to be decreased in MT exposed neurons. Comparable results were observed in cultures of superior cervical ganglia cells (data not shown). Together, these results suggest that the limited, compared with NGF, interface between NGF mimetics and TrkA molecule translates into a somewhat restricted array of downstream signals departing from the receptor.

To clarify the biochemical bases of such functional divarication, we studied in closer detail the phosphorylation pattern of the intracytosolic tail of TrkA chain upon exposure to NGF versus MT2, using monospecific antibodies for the tyrosines $490,674 / 675$, and 785 , known to be critical for the transmission of neurotrophin signal. ${ }^{1,8}$ To this purpose, we used either PC12 cells or the wtTrkA-NIH-3T3 stable transfectants, obtaining superimposable results. Figure $5 \mathrm{a}$ shows that MT2 added to PC12 cells invariably caused phosphorylation of Tyr490, and that Tyr674/675 and Tyr785 underwent minimal activation, while all of them were clearly phosporylated upon exposure to hrNGF. The latter findings indicate that some biologic responses to NGF mimetics are expressed at a lower level, compared with NGF, and drove us to investigate further the biochemical pathways originating from the activation of Tyr490.

It is known that upon phosphorylation of such residue, via sequential involvement of Shc and Ras, the MAP kinase cascade is activated, a pathway central to the death/survival divide in a disparate number of cell types, which comprises kinases often displaying opposing activities. ${ }^{15}$ As NGF has a conspicuous role in the homeostasis of such proteins, ${ }^{16,17}$ we studied the phosphorylation status of extracellular signalregulated kinase (ERK), c-Jun N-terminal kinases (JNK), p38 mitogen-activated protein kinase (MAPK) proteins, and of Akt, another kinase involved in the regulation of cell survival, ${ }^{18}$ in serum-starved PC12 cells exposed to hrNGF or to MT2.
Figure 5b shows that indeed p42/44 ERK and Akt became strongly activated upon addition of either stimulus. Conversely, MT2 - or hrNGF as control - was able to induce a marked dephosphorylation of p38 MAPK in PC12 cells, from sustained levels down to negligible amounts, while JNK activation was reduced, but not at significance levels (Figure 5b).

To better understand the profound modulation of p38 MAPK activation elicited by MT2, we tested whether MKP-1, a phosphatase highly specific for p38 MAPK and also for JNK, ${ }^{17,19}$ could have a role in this setting, as previously observed. ${ }^{17}$ Figure $5 \mathrm{c}$ shows that exposure of serumdeprived PC12 cells to MT2 or hrNGF caused marked increase in MKP-1 protein levels, as early as $30 \mathrm{~min}$ after stimulation. Taken together, this set of experiments is coherent with the observed capacity of MT2 to sustain cell survival in cultures undergoing metabolic derangement.

To confirm the interaction of MT2 with TrkA residues involved in NGF binding and to rule out the involvement of other acceptors, for example, other protein kinase receptors, in the response to MT2, similar studies were repeated on the wild type (WT), F327A, and T352A TrkA-NIH-3T3 stable transfectants. Figure $6 \mathrm{a}$ reports a western blot analysis showing induction of ERK 1/2 phosphorylation by MT2, while Figure $6 \mathrm{~b}$ reports dephosphorylation of p38 MAPK in the same cell cultures. In both instances the observed activity was largely comparable with that induced by NGF and was almost completely abolished by addition of $\mathrm{K} 252 \mathrm{a}$, a classic inhibitor of TrkA catalytic function. As expected, if the T352Aor F327A-TrkA/NIH-3T3 mutants were used to study MT2induced ERK 1/2 and p38 MAPK activation status, the latter was influenced by either mutation, as assessed by western blot analysis (Figures $6 a$ and $b$ ). We also wanted to use a quantitative approach to measure the levels of activated p38 MAPK proteins. The results of this analysis were totally consistent with the western blot approach (Supplementary Figure 1). Thus, at least a substantial part of the biologic activity exerted by MT2 is elicited upon interaction with two of the TrkA amino-acid residues involved in binding the native neurotrophin.

Activity of NGF mimetic on organ cultures of rat hippocampus. Based on the above findings showing a clear-cut activity of MT2 in several in vitro systems, we wanted to assess its ability to rescue NGF deficit in a recently characterized rat hippocampal neuronal model, in which NGF deficit is strictly connected to the activation of the amyloidogenic pathway. ${ }^{7,20}$ In this neuronal in vitro model, accumulation of both amyloid precursor protein (APP) and the 28-kDa active form of presenilin 1 (PS1) (endowed with $\alpha$-secretase activity) is observed as early as $30 \mathrm{~min}$ after administration of neutralizing anti-NGF antibodies; the simultaneous addition of NGF to the cultures prevents such biochemical modifications. We therefore tested whether MT2 was able to mimic the native neurotrophin in preventing amyloidogenesis and neuronal death. Figure 7 a shows that MT2 induced dose-dependent TrkA phosphorylation in such cultures. Moreover, it could indeed abolish the dramatic enhancement in APP generation, at levels comparable with those attained by the addition of NGF. An even stronger 
activity was evident when generation of full-length PS1 or of its 28-kDa enzymatically active form was investigated, as the amounts of both proteins were profoundly modulated in cultures treated with MT2 (Figures $7 b$ and $c$ ); in occasional experiments, it acted more than hrNGF did in parallel cultures. Consistent with the inhibition of amyloidogenic pathway, neurons were strongly protected from death in a dose-dependent fashion (Figures $7 d$ and e). Thus, the

a
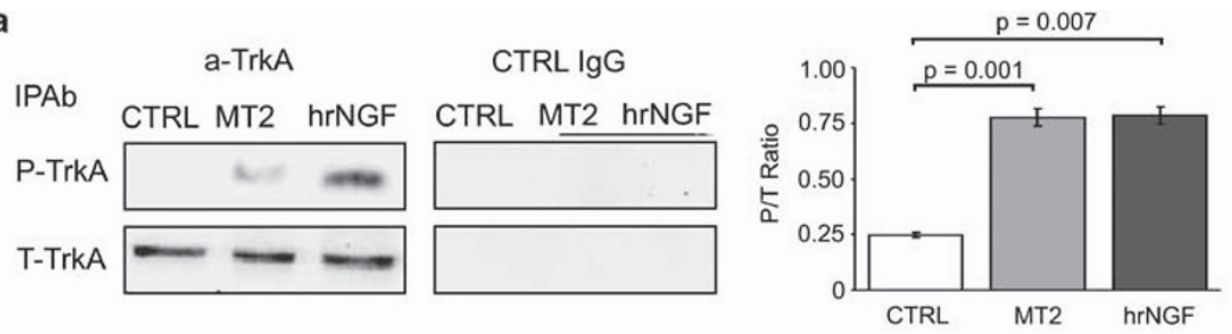

b
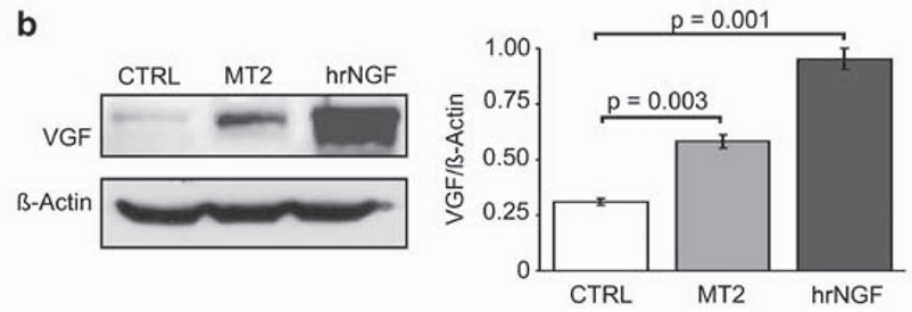

C
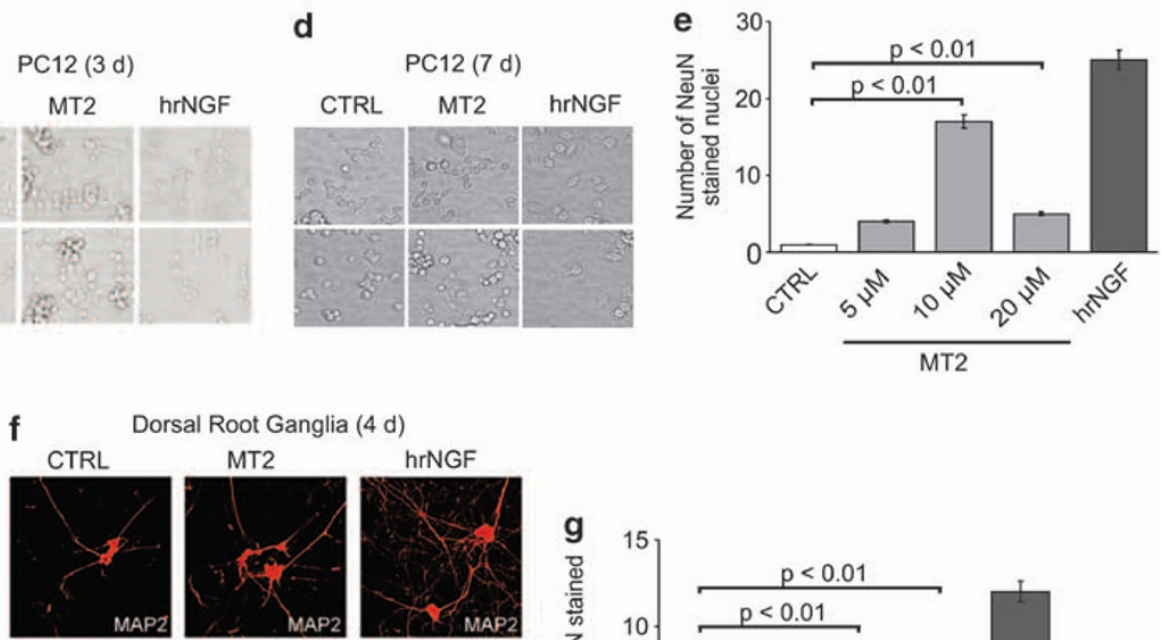

Dorsal Root Ganglia (4 d)
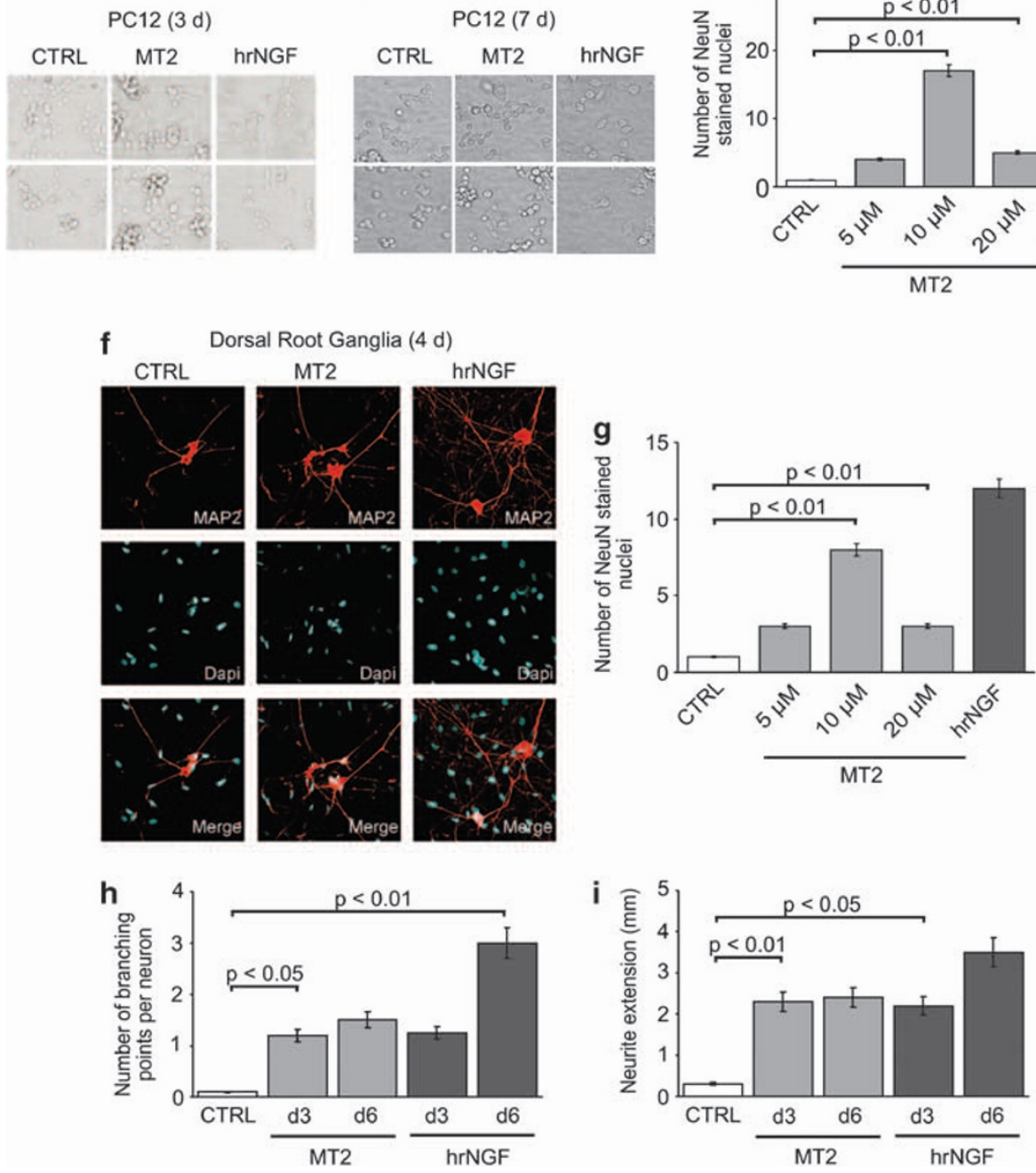
activity of NGF mimetics was confirmed also in a highly representative model of human pathology, a finding which warrants their exhaustive evaluation in in vivo settings.

\section{Discussion}

NGF triggers a complex set of biochemical events in the responding cells, through interaction with TrkA and/or p75 NTR chains. ${ }^{1,3}$ While stimulation of the former chain results in differentiation and/or survival-promoting events, engagement of the latter is associated with generation of pro-apoptotic signals, including that of pro-NGF. ${ }^{21,22}$ To exploit the trophic properties of the neurotrophin, we considered the structural data provided by the NGF/TrkA co-crystallization studies ${ }^{5,23}$ and conceived a library of small molecules, theoretically able to combine with the survival-promoting TrkA receptor on the basis of their overall molecular sizes. The characterization of such library revealed that some of the compounds were active in typical NGF-dependent assays; such properties were at least comparable with those expressed by similar small molecules previously described. ${ }^{24-32}$

That the representative MT2 compound is indeed an NGF mimetic is indicated by several pieces of evidence: (i) it interacts with TrkA $^{+}$cells and displaces binding of iodinated NGF; (ii) it binds to TrkA in cell-free assays, being displaced by hrNGF; (iii) it induces TrkA autophosphorylation and triggers consistent biochemical pathways; (iv) in silico prediction of its binding residues within TrkA molecule indicates amino acids whose mutations abolish its function; and ( $v$ ) K252a, a classic inhibitor of TrkA signaling, modulates its properties.

Particularly important is explaining how small molecules, a tiny fraction of the overall size of NGF, can elicit comparable biochemical consequences. A possible explanation is that binding of small molecules to selected TrkA residues, known to be involved in binding the native neurotrophin, ${ }^{23}$ is able to induce conformational changes extended enough to result in triggering of receptor autophosphorylation, which in turn gives rise to the subsequent cascades. ${ }^{1}$ In addition, it is noteworthy that MT2 most probably interacts with a TrkA monomer, rather than a dimer of the receptor, as indicated by the docking analysis. Quite recently, similar 'monovalent' TrkB agonists have been described by Massa et al., ${ }^{31}$ who suggested that the conformational changes induced by binding directly promote dimerization and, hence, activation of the receptor; if so, then NGF mimetics could position two TrkA monomers at intermolecular distances and spatial relationships, relative to the cell membrane plane, appropriate to align, within the cytosol, the catalytic site of one TrkA molecule with the target tyrosine residues of the other.

On the other hand, the restricted (in terms of amino-acid residues involved) biochemical interaction between NGF mimetics and TrkA may well explain the observed heterogeneity of the biologic response evoked in target cells. In fact, typical differentiation events, such as neurite outgrowth or induction of VGF gene expression in PC12 cells, were incompletely elicited, while a full-blown trophic ability of supporting survival of serum-starved cells was consistently registered, together with a strong activity in the NGF-deprived model of neuronal degeneration in organ cultures of rat hippocampus. Such divarication, rather unexpected, raises critical questions about the molecular mechanisms responsible for the functional properties of NGF mimetics. MT2, the representative molecule we selected, induced a limited, compared with NGF, TrkA phosphorylation, predominantly focussed onto Tyr490, with minimal contributions from Tyr674/675 and Tyr785. Thus, the biochemical pathways departing from the latter residues are incompletely expressed, giving rise to a 'blunted' response, compared with the neurotrophin, which is probably shaped by the combined action of the intensity of pathways originating from Tyr490, together with the paucity of those originating from Tyr674/675 and Tyr 785. This in turn may explain why a complete trophic activity and a reduced differentiative response originate from MT2 signaling. These considerations are particularly relevant in the light of the ample heterogeneity observed in TrkA behavior, as a function of the ligand it engages. For example, amyloid itself was recently shown to interact with TrkA, to convey signals leading to neuronal cell death. ${ }^{33}$ We suggest that at the basis of this heterogeneity lies a complex pattern of phosphorylation/dephosphorylation of the tyrosines within the intracytosolic tail of Trk A, which was so far assessed mainly by using antibodies specific for few phosphopeptides only.

The biochemical pathways triggered by MT2 and leading to functional modulation of the MAPK family of proteins and of Akt were geared at similar, maximal intensity. These enzymes collectively have a critical role in several cellular processes,

Figure 4 NGF mimetic activities expressed by MT2. (a) Effect of MT2 on TrkA autophosphorylation. PC12 cells were incubated with $10 \mu \mathrm{M}$ MT2 or $4 \mathrm{nM} \mathrm{hrNGF.} \mathrm{Cell}$ lysates were immunoprecipitated with a-TrkA or with control IgG antibodies, blotted on nitrocellulose filter, and stained with anti-PY antibodies. (b) Effect of MT2 on VGF production by PC12 cells. PC12 cells, stimulated with $10 \mu \mathrm{M}$ MT2 or $4 \mathrm{nM}$ hrNGF, were lysed, blotted, and stained with anti-VGF antibodies. Results of one representative experiment out of three performed are shown in $\mathbf{a}$ and $\mathbf{b}$. (c-e) MT2 induces an NGF-like growth arrest in PC12 cells. Cells were exposed to MT2 (5-20 $\mu$ M) and the number of neuronal nuclei stained with a specific neuronal marker (NeuN) was assessed after 7 days. (c and d) phase contrast microscope analysis of PC12 cells exposed to MT2 $10 \mu \mathrm{M}$ for 3 (c) or 7 days (d). At day 3, MT2- exposed PC12 cells appear to be aggregated into clumps with shorter and limited numbers of neuritic processes, compared with the corresponding NGF-differentiated $(2 \mathrm{nM})$ samples (c). All these events appear more prominent at day 7 , where most of MT2-treated cells are aggregated to form larger clusters, with neuritic processes significantly shorter than those observed in the corresponding NGF-treated cells (d); (e) number of NeuN + cells after 7 days of culture $(n=6)$. Ten micromolar MT2 results to be the highest active concentration. (f-i) NGF-like neuronal differentiating activity in DRG neurons: (f) Neuronal nuclei were assessed following stimulation for 4 days with MT2 $(10 \mu \mathrm{M})$ and hrNGF $(2 \mathrm{nM})$. MAP2 positive neuritic processes are stained in red (scale bar: $25 \mu \mathrm{m})$. (g) Neuronal nuclei assessed following 4 days of stimulation with MT2 $(5-20 \mu \mathrm{M})$ and hrNGF $(2 \mathrm{nM})$. (h-i) The number of branching points (h) and Neurite extension (i) in cells stimulated with $2 \mathrm{nM}$ NGF or $10 \mu \mathrm{M}$ MT2 were recorded after the indicated times. Images were analyzed using the Olympus inverted microscope (Olympus Corporation, Tokyo, Japan) or NIH ImageJ (NIH, Bethesda, MD, USA). Neurites were viewed with a $\times 20$ objective, images were projected onto a video monitor, and neurite lengths were traced with a digitizing tablet while being viewed on the monitor. Ten DRG neurons were analyzed for each slide and the experiments were repeated at least three times. Statistical significance was determined with independent $t$-test and one-way ANOVA. For distribution, the data were presented as mean S.E.M. 

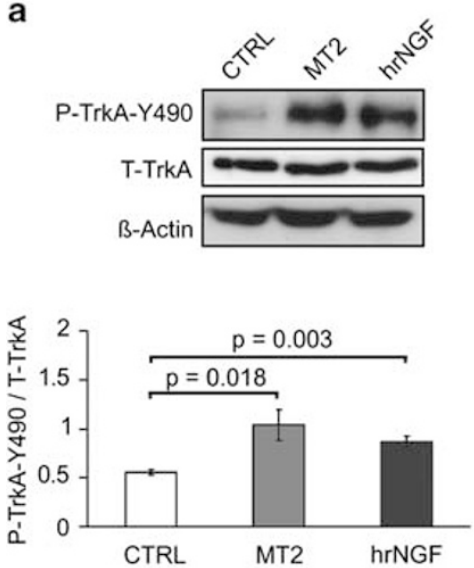
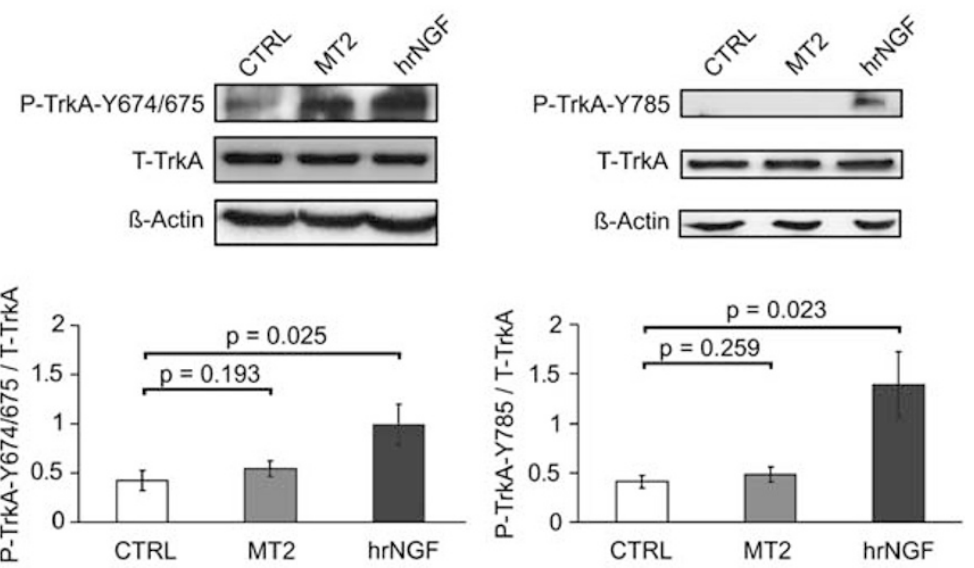
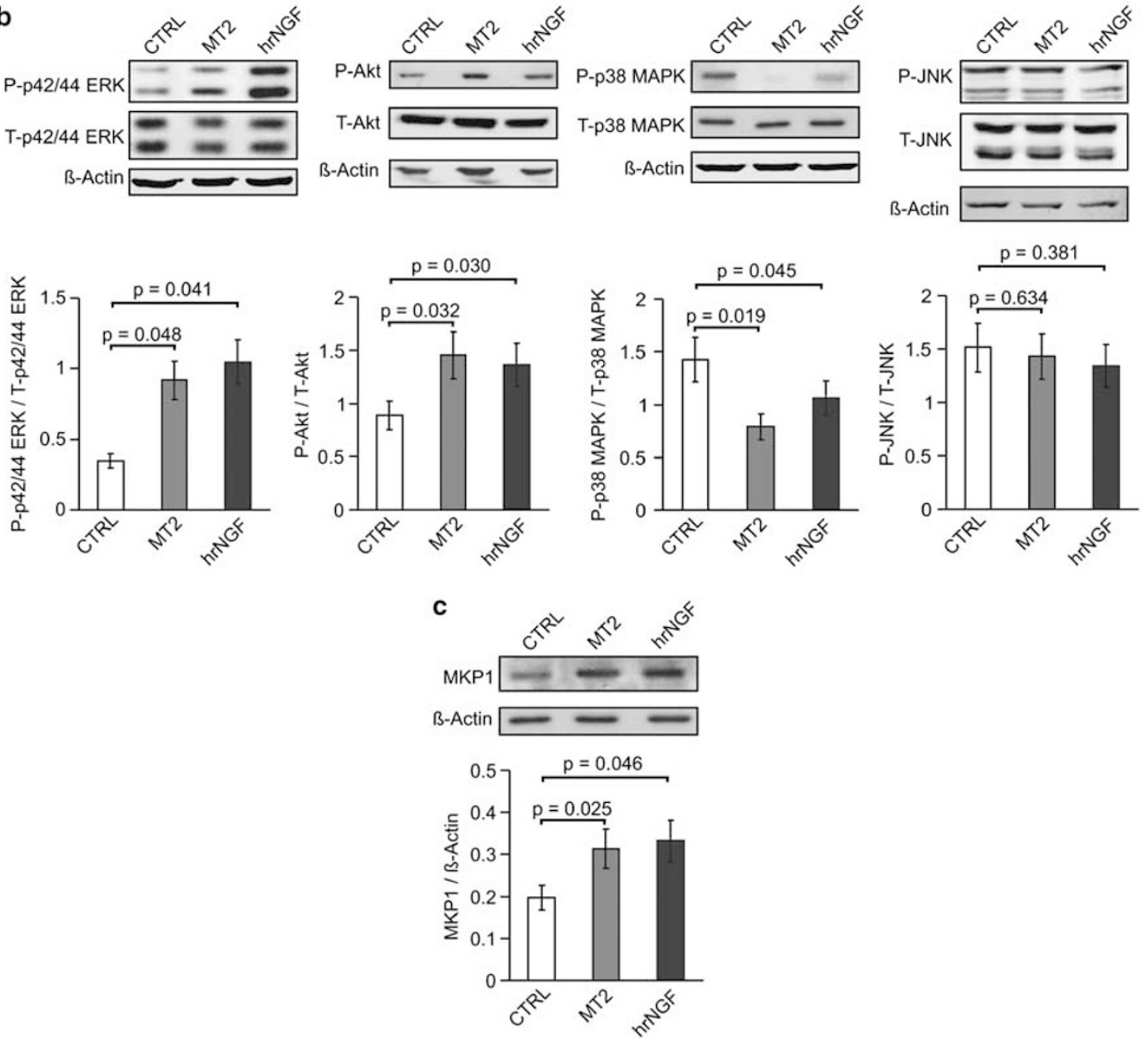

Figure 5 Biochemical pathways induced by MT2 in PC12 cells. (a) TrkA phosphorylation. Serum-starved PC12 cells were stimulated with $10 \mu \mathrm{M}$ MT2, or $4 \mathrm{nM}$ hrNGF as positive control, for $15 \mathrm{~min}$. Cells lysates were blotted with antibodies to P-Y490, P-Y674/675, P-Y785 and with anti-actin as loading control. Membranes were stripped and stained with anti-total TrkA IgG. The relative histograms represent the data of densitometric analysis and are expressed as the ratio between phosphoprotein $(P)$ and total protein $(T)$ of five different experiments (mean \pm S.E.). Statistical analysis was performed by paired Student's $t$-test. (b) Kinases phosphorylation. Serum-starved PC12 cells were stimulated with $10 \mu \mathrm{M} \mathrm{MT2}$, or $4 \mathrm{nM}$ hrNGF, for $30 \mathrm{~min}$. Cell lysates were blotted with rabbit anti-P-ERK, anti-P-Akt, anti-P-p38 MAPK, anti-P-JNK. Then, membranes were stripped and stained with antibodies to the respective total protein and with anti-actin antibodies as loading control. The relative histograms represent the data of densitometric analysis and are expressed as the ratio between phosphoprotein $(P)$ and total protein $(T)$ of five different experiments (mean \pm S.E.). Statistical analysis was performed by paired Student's $t$-test. (c) Phosphatase. Serum-starved PC12 cells were stimulated with $10 \mu \mathrm{M}$ MT2, or $4 \mathrm{nM}$ hrNGF as positive control, for 30 min. Cell lysates were blotted with rabbit anti-MKP1 IgG and anti-actin antibodies as loading control. The relative histogram represents the data of densitometric analysis and is expressed as the ratio between MKP1 expression and actin of five different experiments (mean \pm S.E.). Statistical analysis was performed by paired Student's $t$-test 
a
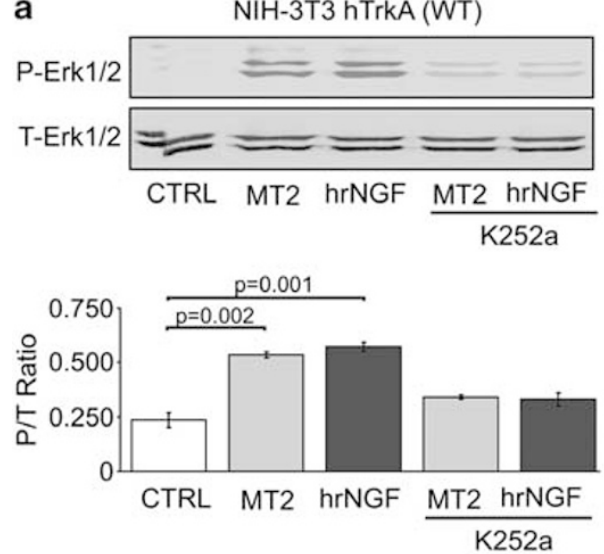

NIH-3T3 hTrkA-T352A
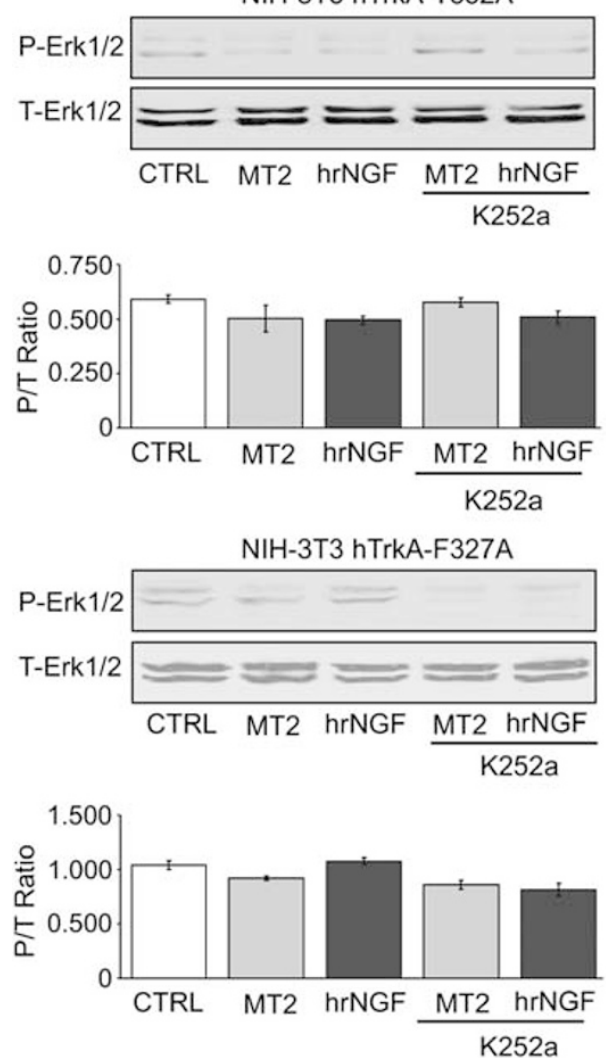

b
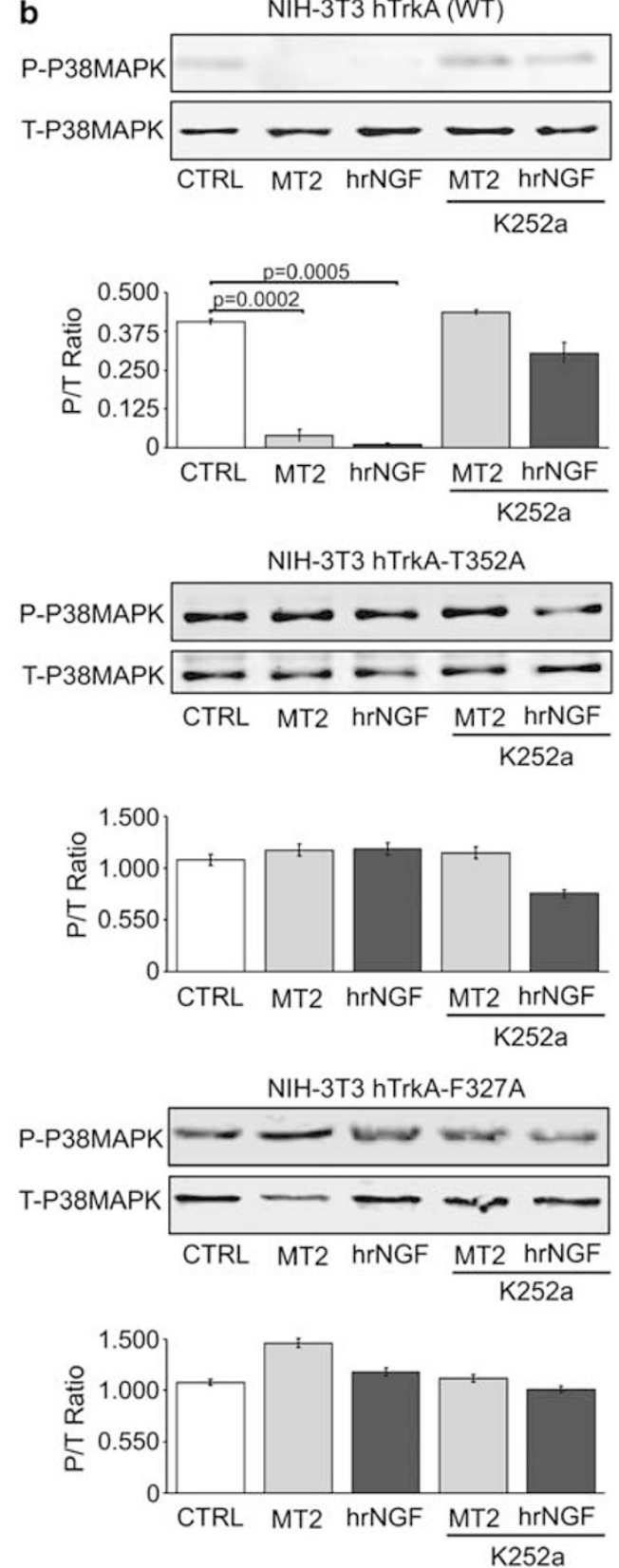

Figure 6 Biochemical pathways induced by MT2 in WT TrkA-NIH-3T3 or mutants. NIH-3T3 cells, stably transfected with full-length WT human TrkA, T352A, or F327A TrkA mutants, were cultured in serum-free medium and incubated with $10 \mu \mathrm{M}$ MT2 or $4 \mathrm{nM}$ hrNGF, in the presence or absence of K252a. Cell lysates were blotted with rabbit anti-P-ERK (a) and anti-P-p38 MAPK (b). Then, membranes were stripped and stained with antibodies to the respective total protein. The relative histograms represent the densitometric analysis. Data are expressed as ratio between phosphoprotein $(P)$ and total protein $(T)$ of three different experiments (mean \pm S.E.). Statistical analysis was performed by paired Student's $t$-test

including the fine tuning of death/survival divide (reviewed in Kim et $a .^{15}$ ), and are therefore important for understanding the differentiation-inducing versus trophic functions of neurotrophins or their analogs. The paramount differentiation event occurring in response to NGF in sensitive cells, like DRG neurons, is neurite formation, a process whereby ERK 1/2 proteins become strongly activated and act on their nuclear targets to bring about a part of the whole process, which is driven to completion in concert with other signaling molecules, enrolled upon phosphorylation of multiple TrkA tyrosines.
By contrast, the role of MAPK proteins in maintenance of survival, particularly in conditions of metabolic stress (e.g., survival factor deprivation, sustained ROS generation, or glutamate-induced excitotoxicity), presents a diverging behavior; in fact, while activation of ERK $1 / 2$ proteins is associated with a protective function, concurring to inhibit the apoptotic process, a strong correlation between p38 MAPK or JNK activation and, the intensity of the apoptotic process is consistenly observed. ${ }^{15}$ Depending on the nature of the metabolic stress, the afferent branches of MAP kinases 

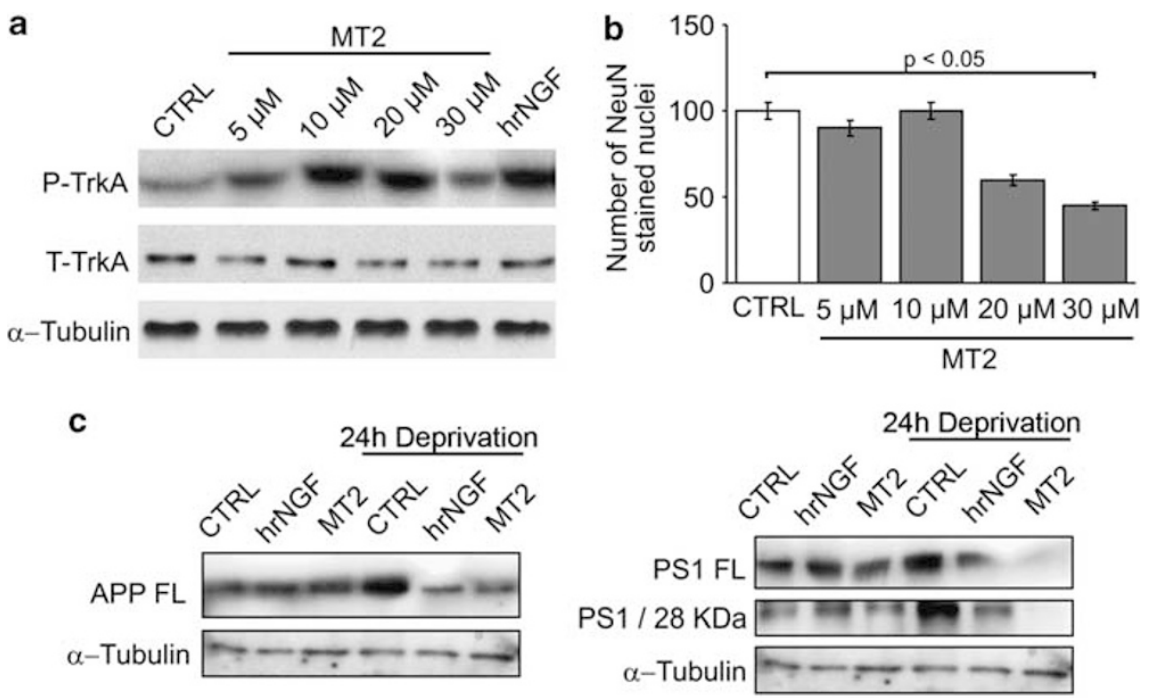

\begin{tabular}{|c|c|}
\hline \multicolumn{2}{|c|}{ Condensed nuclei } \\
\hline CTRL & $2.3 \pm 0.18$ \\
\hline hrNGF & $2.4 \pm 0.19$ \\
\hline Deprivation & $4.8 \pm 0.26$ \\
\hline Dep. + hrNGF & $2.6 \pm 0.22$ \\
\hline Dep. + MT2 $5 \mu \mathrm{M}$ & $3.9 \pm 0.13$ \\
\hline Dep. + MT2 $10 \mu \mathrm{M}$ & $2.8 \pm 0.12$ \\
\hline Dep. + MT2 $20 \mu \mathrm{M}$ & $3.6 \pm 0.28$ \\
\hline
\end{tabular}

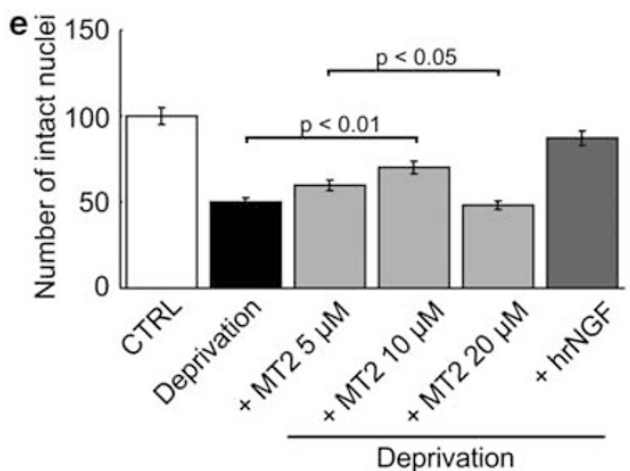

Figure 7 MT2 protects neurons from A $\beta$ amyloid-mediated death in NGF-deficient neurons. (a and $\mathbf{b}$ ) $3-4$ days cultured hippocampal neurons were exposed to $2 \mathrm{nM}$ NGF or to MT2 $(5-30 \mu \mathrm{M})$ and the highest active concentration of MT2 evaluated as induction of TrkA phosphorylation by western blot analysis with anti-phosphorylated (P) and anti total (T) Trk-A antibodies or by counting the number of NeuN stained nuclei (b). (c and d) hippocampal neurons were deprived of NGF by exposure to anti-NGF antibodies $(30 \mu \mathrm{g} / \mathrm{ml})$ for $24 \mathrm{~h}$ and incubated in the presence or absence of $10 \mu \mathrm{M} \mathrm{MT2}$ or $2 \mathrm{nM} \mathrm{hrNGF}$. Cells were lysed and western blot analysis performed with antibodies against APP full-length (c) and PS1 $28 \mathrm{kDa}$ N-terminal fragment (d). (e and f) Hippocampal neurons were deprived of NGF by exposure to anti-NGF antibodies ( $30 \mu \mathrm{g} / \mathrm{ml}$ ) for $24 \mathrm{~h}$ and then treated with concentrations of MT2 ranging from 5 to $30 \mu \mathrm{M}$ or $2 \mathrm{nM}$ hrNGF. The percentage of alive neurons was obtained by counting the number of intact nuclei (d) or alternatively by counting the number of condensed nuclei (e). Ctrl, neurons not exposed to NGF or MT2; NGF, neurons exposed for $48 \mathrm{~h}$ to NGF; MT2, neurons exposed for $48 \mathrm{~h}$ to MT2 $(10 \mu \mathrm{M})$; Dep, neurons deprived of NGF for 24 hours; Dep + NGF, neurons washed with NGF-free media and immediately exposed to NGF containing media; Dep + MT2 neurons washed with NGF-free media and immediately exposed to MT2-containing media. Statistical analysis was performed by Newman-Keuls test $(N=4)$, $P<0.05$. Consistent with the inhibition of the amyloidogenic pathway, neurons were completely protected from death

activation may originate from diverse pathways, for example, ASK-1 kinase, ${ }^{15}$ Rho GTPase, ${ }^{34}$ or AMPKinase ${ }^{35}$; likewise, the efferent branches are manifold, for example, Bcl-2 family proteins, ${ }^{36} \mathrm{p} 53^{35}$, or various nuclear substrates. In this connection, the strong upregulation of MKP-1 protein that we observed in cells treated with MT2 is completely consistent with modulation of p38 MAPK phosphorylation and with the overall survival rate the compound is able to sustain.

Such critical participation of p38 MAPK or JNK in the intrinsic pathway of apoptosis is well documented in several other, nonneural contexts, particularly in the heart. ${ }^{37}$ Consistently, the activity of NGF in modulating cellular damage of ischemic heart is remarkable ${ }^{38}$ and recapitulates the antiapoptotic properties of neurotrophins in nonneural cells and tissues. In this connection, it is worth stressing that the profound activity of NGF mimetics upon p38 MAPK and, relevantly, its antiamyloidogenic activity in the NGF-deprived hippocampal neurons open up an array of potential therapeutic opportunities addressing important medical needs.

\section{Materials and Methods}

Cell lines and cell cultures. Rat pheochromocytoma PC12 cells were cultured in RPMI-1640 (Sigma Aldrich, St. Louis, MO, USA), supplemented with $10 \%$ horse serum, $5 \%$ fetal bovine serum (FBS). Human prostate carcinoma cell line PC-3 were grown as monolayer in Nutrient Medium F12 (Ham's F-12). $\mathrm{NIH}-3 \mathrm{~T} 3$ were cultured in DMEM supplemented with $10 \%$ FBS. All cell lines were obtained from ATCC. Culture media were supplemented with $2 \mathrm{mM}$ L-glutamine and $50 \mathrm{IU} / \mathrm{ml}$ penicillin, and $50 \mu \mathrm{g} / \mathrm{ml}$ streptomycin.

Hippocampal neurons were prepared from embryonic day 17-18 (E17/E18) from timed pregnant Wistar rats (Charles River Laboratories, Wilmington, MA, USA), as previously reported, ${ }^{20} 3-4$ days plated neurons were exposed to or deprived of NGF according to the procedures described. ${ }^{33}$

DRG were prepared from P1-P3 rat pups, as previously reported ${ }^{39}$ and plated in DMEM culture medium with $5 \%$ heat-inactivated horse serum, NGF $(50 \mathrm{ng} / \mathrm{ml}$ final concentration) and penicillin/streptomycin. 


\section{Cell viability assay}

Hippocampal neurons. Viable hippocampal neurons were quantified by counting the number of intact nuclei or by the DNA-binding fluorochrome DAPI (Molecular Probes, Carlsbad, CA, USA) (condensed nuclei). The stained cells were examined immediately with a standard fluorescence microscope.

PC12 cells. Compounds were prepared as $10 \mathrm{mM}$ stock solution using ethanol as a solvent. MTT reduction assay was carried out according to the manufacturer instructions. Briefly, cells were plated at $5 \times 10^{3}$ cells per well in $100 \mu \mathrm{l}$ of serumfree medium in 96-well tissue culture plates, and treated in triplicate with $0.1-10 \mu \mathrm{M}$ of test compounds for 3 days or with $4 \mathrm{nM}$ hrNGF (Calbiochem, Darmstadt, Germany) as positive control. MTT (Sigma Aldrich) was added to a final concentration of $0.5 \mathrm{mg} / \mathrm{ml}$, and the incubation was prolonged for further $4 \mathrm{~h}$. Cells were lysed by adding $100 \mu \mathrm{l}$ of lysis buffer (20\% SDS, $50 \%$ $\mathrm{N}, \mathrm{N}$-dimethylformamide, $\mathrm{pH} 4.7$ ) and reduced MTT was solubilized with $100 \mu \mathrm{l}$ of isopropyl alcohol. The optical density of the resulting solution of converted dye was measured in a microplate spectrophotometer at a wavelength of $570 \mathrm{~nm}$ with background subtraction at $690 \mathrm{~nm}$. The survival index was calculated as (MTT incorporation of stimulated cultures/background cultures) $\times 100$.

Analysis of axon length and branching points. Cultured neurons were fixed with $4 \%$ paraformaldehyde in PBS, $\mathrm{pH} 7.4$, for $1 \mathrm{~h}$, and permeabilized and blocked with PBS containing $0.1 \%$ Triton X-100 and $1 \%$ goat serum. To determine the response to NGF, the number of neurons, stained by a specific neuronal marker (NeuN, Millipore, Billerica, MA, USA), was assessed. Dendrites and neuritis were marked with anti MAP-2 antibody (Sigma Aldrich).

Images were analyzed using the Olympus inverted microscope (Olympus Corporation) or $\mathrm{NIH}$ ImageJ for the following parameters: number of neurons with neuritis, neuritic length, and number of branching points. Neurites were viewed with a $\times 20$ objective, images were projected onto a video monitor, and neurite lengths were traced with a digitizing tablet while being viewed on the monitor.

Each condition was repeated at least three times, and in a single experiment of each condition, 10 DRG neurons were analyzed. Statistical significance was determined with independent $t$-test and one way ANOVA. For distribution, the data were presented as mean S.D., and for the rest of the analysis, the data were presented as mean S.E.M.

Apoptosis assay. PC12 cells were cultured in serum-free medium for $16 \mathrm{~h}$ in the presence or absence of MT2 $(0.1-100 \mu \mathrm{M})$ or $4 \mathrm{nM}$ hrNGF as internal standard. Cell were washed, stained with FITC Annexin-V (BD Pharmingen, San Diego, CA, USA) and Propidium lodide (Roche Diagnostics, Indianapolis, IN, USA) and analyzed by a FACScan (Becton Dickinson, Franklin Lakes, NJ, USA).

Cell differentiation and cell proliferation assay of PC12 cells. Differentiation was achieved by placing PC12 in petri dishes in the presence of $5 \%$ horse serum and $2.5 \%$ fetal bovine serum (GIBCO, Carlsbad, CA, USA) and NGF $(2 n M)$ for 10-12 days. To ensure maximum bioavailability, NGF and serum were replaced every 2 days for 10-12 days. The numbers of differentiated PC12 cells were assessed by counting the nuclei stained with NeuN marker (Millipore). Cell proliferation was measured by counting the number of intact nuclei stained with DAPI and analyzed by a fluorescent microscope. PC12 differentiated cells and neuronal primary culture after treatments were fixed with $4 \%$ paraformaldheyde for $15 \mathrm{~min}$ at room temperature, washed in PBS, $\mathrm{pH} 7.5$, and then permeabilized with $0.2 \%$ Triton $\mathrm{X}-100$ and $\mathrm{Tris} / \mathrm{Cl}, 0.1 \mathrm{M} \mathrm{pH} 7.5$, for $5 \mathrm{~min}$.

To analyze neurite outgrowth, PC12 cells were seeded onto 12-well poly-Llysine-coated plates at a density of $1 \times 10^{5}$ cells per plate 1 day before treatment. The next day, cells were treated with $2 \mathrm{nM}$ of NGF for $24 \mathrm{~h}$ or with $0.5-20 \mu \mathrm{M} \mathrm{MT2}$, and the extent of neurite outgrowth was assessed by counting the number of cells marked with NeuN (Chemicon, Billerica, MA, USA) and MAP2 (Sigma Aldrich) antibodies. Cells with neurites were defined as cells possessing at least one neurite more than one cell body diameter in length.

Proliferation assay of PC3 cells. PC3 cells were cultured in triplicate in 24-well plates at the final concentration of $1 \times 10^{4} \mathrm{celll} / \mathrm{ml}$ (final volume of $500 \mu \mathrm{l}$ ) in nutrient medium F12 (Ham's F-12) in the presence or absence of $0.1-10 \mu \mathrm{M}$ of the compounds or of $4 \mathrm{nM}$ of hrNGF as internal standard. Cells were incubated for $60 \mathrm{~h}$ in humidified, $5 \% \mathrm{CO}_{2}$ atmosphere. At the end of incubation $0.5 \mu \mathrm{Ci}$ of ${ }^{3} \mathrm{H}$-thymidine were added to each well for $8 \mathrm{~h}$. Cells were then washed six times with PBS, lysed with $0.1 \%$ Triton $\mathrm{X}-100$ in $0.1 \mathrm{M}$ phosphate buffer, and the radioactivity was recorded in a $\beta$-scintillation counter.
Construction of TrkA Mutants. The full-length human-TrkA in pCDNA3 vector was kindly provided by Dr A Levi (CNR) Roma, Italy. F327A and T352A TrkA mutants were obtained by using the QuikChange site-directed mutagenesis kit (Stratagene, Santa Clara, CA, USA) by using the following primers:

F327A-FW (5'-GCTCAATGAGACCAGCGCCATCTTCACTGAGTTCCTGG-3'), F327A-RV (5'-CCAGGAACTCAGTGAAGATGGCGCTGGTCTCATTGAGC-3'), T352A-FW (5'-GCGCCTCAACCAGCCCGCCCACGTCAACAACGGCAA-3'), T352A-RV (5'-TTGCCGTTGTTGACGTGGGCGGGCTGGTTGAGGCGC-3').

All of the products were sequenced by using the BigDye Terminator Kit (Applied Biosystems, Carlsbad, CA, USA).

Transfections of NIH-3T3 with WT or mutant TrkA was obtained by LipofectAMINE reagent (Life Technologies, Carlsbad, CA, USA), following the manufacturer's instruction. Stable transfected clones were selected using neomycin for 2 weeks.

Docking analysis of MT2 on TrkA. The docking simulations were performed on a model of TrkA ligand binding domain obtained deleting the NGF from the NGF-TrkA co-crystal (PDBcode: 1WWW). Docking was performed as a global energy optimization by means of the biased probability Monte Carlo stochastic procedure as implemented in ICM3.6 and the binding energy was assessed by the ICM empirical standard scoring function. ${ }^{13}$ The molecular system was described using internal coordinate variables. Hydrogen atoms and missing heavy atoms were added. Zero occupancy side chains and polar hydrogen atoms were optimized and assigned the lowest energy conformations. Tautomeric states of histidines and the positions of asparagine and glutamine side chain amidic groups were optimized to improve the $\mathrm{H}$-bond pattern. The ligand was assigned MMFF force field atom types, its three dimensional structure was generated from 2D coordinates, and it was subjected to Cartesian minimization. The binding site was defined selecting all the residues with at least one non-hydrogen atom within $3.5 \AA$ from the largest envelope predicted by the Pocketome Gaussian Convolution algorithm. ${ }^{40}$ The binding pocket was described by five $0.5 \AA$ spacing potential grid maps, representing van der Waals potentials for hydrogens and heavy atoms, electrostatics, hydrophobicity, and hydrogen bonding. A soft form of the van der Waals potentials truncated at $4 \mathrm{kcal} / \mathrm{mol}$ was adopted.

Western blot analysis. PC12, WT or mutant TrkA NIH-3T3 cells, were stimulated for $15-30$ min with $10 \mu \mathrm{M}$ MT2 or $4 \mathrm{nM}$ hrNGF as positive control. In selected experiments K252A (Sigma Aldrich) was used at the final concentration of $30 \mathrm{nM}$. DMSO was used as vector control; cells were lysed with RIPA buffer ( $50 \mathrm{mM}$ Tris- $\mathrm{HCl}$, pH 7.4; $150 \mathrm{mM} \mathrm{NaCl}$; 2 mM EDTA; $1 \mathrm{mM} \mathrm{NaF;} 1 \mathrm{mM}$ sodium orthovanadate, $1 \% \mathrm{NP}-40$ ) in the presence of phosphatase inhibitor cocktail 2 and 3, protease inhibitor cocktail (Sigma Aldrich) and centrifuged at 12000 r.p.m. for $15 \mathrm{~min}$. Protein concentration was determined by using a Micro BCA protein assay kit (Pierce, Rockford, IL, USA). Fifty micrograms of proteins was loaded onto SDS-PAGE and blotted onto nitrocellulose filters (GE Healthcare, Fairfield, CT, USA). Membranes were stained with rabbit antibodies anti-P-TrkA-Y490, anti-PTrkA-Y674/675, anti-P-TrkA-Y 785, anti-P-Akt, anti-P-ERK 1/2, and anti-P-SAPK/ JNK (Cell Signaling Technology, Danvers, MA, USA), anti-MKP1 (Santa Cruz Biotechnology, Santa Cruz, CA, USA), anti-VGF (OriGene, Rockville, MD, USA) and mouse anti $\beta$-actin (Santa Cruz Biotecnology); all the antibodies were used at $1: 1000$, final dilution. HRP-coniugated anti-rabbit $\operatorname{lgG}$ (GE Healthcare) or HRP-conjugated anti mouse IgG (Santa Cruz Biotecnology) were used as secondary antibodies at 1:2000 final dilution. The reactions were visualized by the $\mathrm{ECL}$ detection system as recommended by the manufacturer (GE Healthcare). Membranes were stripped at $65^{\circ} \mathrm{C}$ in stripping buffer ( $100 \mathrm{mM}$ Mercaptoethanol, $2 \% \mathrm{SDS}$ and $62.5 \mathrm{mM}$ Tris- $\mathrm{HCl} \mathrm{pH} \mathrm{6.8)} \mathrm{for} 30 \mathrm{~min}$ and stained with anti-hTrkA, anti-hAkt, anti-hERK 1/2, and anti-hSAPK/JNK (Cell Signaling Technology). After staining with HRP-coniugated anti-rabbit IgG, the reactions were visualized by the $E C L$ detection system.

For the detection of APP and PS1, rat hippocampal neurons were exposed to or deprived of NGF according to the procedures described by Matrone et al. ${ }^{20}$ Neurons were exposed to NGF ( $50 \mathrm{ng} / \mathrm{ml})$ or $10 \mu \mathrm{M}$ MT2 for $48 \mathrm{~h}$. Cells were lysed and equal amounts $(10-30 \mu \mathrm{g})$ of proteins were separated on $4-12 \%$ Bis-Tris SDS-PAGE gels or $4-20 \%$ Tris-Gly gels (Invitrogen, Carlsbad, CA, USA), blotted onto PVDF membranes (Millipore) and incubated overnight with the appropriate primary antibody. The antibodies used were: mouse monoclonal anti-APP (22C11) 
(Chemicon); mouse MAb anti-PS1 N-terminus (clone APS11) (Novus Biologicals, Littleton, CO, USA); anti- $\alpha$ tubulin antibody (Sigma Aldrich).

Multiplex assay technology. $2 \times 10^{6}$ TrkA-NIH-3T3 cells were lysed using Bio-Plex cell lysis kit, containing protease and phosphatase inhibitors. Protein concentration was determined by BCA protein assay kit (Pierce). Phosphoproteins and the correspondent total proteins were measured using Bio-Plex phosphoprotein Detection kit (Bio-Rad Laboratories, Benicia, CA, USA) according to the manufacturer's recommendations on BIOPLEX apparatus (Bio-Rad, Hercules, CA, USA).

TrkA autophosphorylation. PC12 cells and TrkA-NIH-3T3 cells were equilibrated in serum-free medium for $2 \mathrm{~h} .5 \times 10^{6}$ cells were then stimulated with $10 \mu \mathrm{M}$ of selected compounds or with $4 \mathrm{nM}$ hrNGF as positive control for $15 \mathrm{~min}$. Cells were then lysed with $10 \mathrm{mM}$ HEPES, $142.5 \mathrm{mM} \mathrm{KCl}, 5 \mathrm{mM} \mathrm{MgCl}$, $1 \mathrm{mM}$ EGTA, $50 \mu \mathrm{g} / \mathrm{ml}$ leupeptin, $30 \mu \mathrm{g} / \mathrm{ml}$ aprotinin, $1 \mathrm{mM}$ PMSF, $0.25 \%$ Triton $\mathrm{X}-100$. Protein concentration was evaluated by Bradford assay. Two hundred fifty micrograms of cell lysates was precleared with Protein A sepharose (GE Healthcare), immunoprecipitated with $2 \mu \mathrm{g} / \mathrm{ml}$ of rabbit a-TrkA antibodies (Genzyme, Cambridge, MA, USA) or with $2 \mu \mathrm{g}$ of control rabbit IgG and Protein A Sepharose, eluted in Laemmli sample buffer, loaded on 10\% SDS-PAGE and blotted onto nitrocellulose filters. Trk-autophosphorylation was evidenced by using rabbit anti-PTyr (PY350) (Santa Cruz Biotechnology). Membranes were stripped in stripping buffer at $65^{\circ} \mathrm{C}$ and stained with mouse anti-hTrk-A (Santa Cruz Biotechnology).

Alternatively, PC12 cells or TrkA-NIH-3T3, cultured as above, were lysed in RIPA buffer in the presence of phosphatase inhibitor cocktail 2 and 3 , and protease inhibitor cocktail, and then blotted onto nitrocellulose filters (see above). Western blot analysis was performed by using rabbit anti-P-TrkA-Y490, P-Y674/675 and P-Y785 antibodies (Cell Signaling Technology).

MT2 radiolabeling. In all, $4.14 \mathrm{mCi}$ of [3H]MeNs solution $(0.053 \mu \mathrm{mol})$ were concentrated under nitrogen flow and $30 \mu \mathrm{l}$ of $0.53 \mu \mathrm{mol}$ MT2 sodium salt in DMSO were added. The mixture was heated at $40^{\circ} \mathrm{C}$ for $5 \mathrm{~min}$, diluted $1: 2$ with $\mathrm{H}_{2} \mathrm{O}$ and loaded over a filter pre-equilibrated with $100 \% \mathrm{EtOH}(5 \mathrm{ml})$ and water $(12 \mathrm{ml})$. After washing with $25 \% \mathrm{EtOH}$ in water labeled MT2 was extracted through $100 \%$ ethanol, concentrated under nitrogen flow, filtered on silica gel, washed with AcOEt $(2 \times 1 \mathrm{ml})$, again concentrated under nitrogen flow and resuspended with $100 \% \mathrm{EtOH}$. Specific activity was determined as the ratio between total and eluted radioactivity. Mean specific activity of ${ }^{3} \mathrm{H}-\mathrm{MT} 2$ was $21.5 \mu \mathrm{Ci} / \mathrm{nmole}$.

\section{Binding assays}

Displacement of ${ }^{125}$ I-hrNGF by MT2. PC12 cells were seeded onto 24-well plates and equilibrated with HKR medium (10 mM HEPES, $125 \mathrm{mM} \mathrm{NaCl}, 4.8 \mathrm{mM}$ $\mathrm{KCl}, 1.3 \mathrm{mM} \mathrm{CaCl}_{2}, 1.2 \mathrm{mM} \mathrm{MgSO}_{4}, 1.2 \mathrm{mM} \mathrm{KH}_{2} \mathrm{PO}_{4}, 1 \mathrm{~g} / \mathrm{l}$ glucose, $1 \mathrm{~g} / \mathrm{l} \mathrm{BSA}$ ). Cells were incubated in triplicate for $2 \mathrm{~h}$ at $4^{\circ} \mathrm{C}$ in HKR medium with $0.1 \mathrm{nM}^{125}$ NGF in the presence or absence of different concentrations of MT2 (100-0.05 $\mu \mathrm{M})$ of hrNGF $(0.01-10 \mathrm{nM})$. Cells were washed with PBS and lysed with $0.25 \mathrm{~N}$ $\mathrm{NaOH}, 0.1 \% \mathrm{SDS}$. Unbound radioactivity and specific cell bound radioactivity were recorded by a $\gamma$-counter and data were analyzed by using the ORIGIN software (OriginLab Corporation, Northampton, MA, USA) (dose-response curve).

MT2 binding on TrkA extracellular domain (ECD). One microgram of purified TrkA ECD proteins (Sino Biological Inc., Beijing, PRC) were incubated in 96-well plates with different concentrations of ${ }^{3} \mathrm{H}-\mathrm{MT} 2(0.12 \mu \mathrm{M}-3 \mathrm{nM}$; mean specific activity $21.5 \mu \mathrm{Ci} / \mathrm{nmole}$ ) at $4^{\circ} \mathrm{C}$ for $10 \mathrm{~min}$ in $0.1 \mathrm{ml}$ of binding buffer (50 mM Na-K phosphate), pH 7.1, $200 \mathrm{mM} \mathrm{NaCl}$, in the presence or absence of 100-fold excess MT2. The reaction mixture was then harvested on a filter paper (Perkin Elmer, Waltham, MA, USA) and washed with $3 \times 5 \mathrm{ml}$ of $100 \mathrm{mM}$ Tris, $\mathrm{pH}$ 7.1. Filters were dried and radioactivity recorded by liquid scintillation counter. Specific binding was calculated for each experimental point, and data were analyzed by the ORIGIN software (one site binding).

MT2 radioligand binding studies on cells. TrkA or mock transfected $\mathrm{NIH}$ $3 \mathrm{~T} 3$ cells were plated at $2 \times 10^{5}$ cells/well in 24 -well plate for $24 \mathrm{~h}$, washed and equilibrated in HKR binding medium for $30 \mathrm{~min}$ at $4^{\circ} \mathrm{C}$. Cells were then incubated with $10-0.01 \mu \mathrm{M}$ of ${ }^{3} \mathrm{H}-\mathrm{MT} 2$, specific activity $21.5 \mu \mathrm{Ci} / \mathrm{nmole}$, in the presence or absence of 100 -fold excess unlabeled MT2 or $4 \mathrm{nM}$ hrNGF for $2 \mathrm{~h}$ at $4^{\circ} \mathrm{C}$. Cells were washed, lysed with $0.25 \mathrm{~N} \mathrm{NaOH}, 0.1 \%$ SDS and, unbound and specific cell-bound radioactivity were recorded through liquid scintillation counting. Data were analyzed by the ORIGIN software (one site binding).
MT2 radioligand internalization studies. $2 \times 10^{5}$ TrkA-NIH-3T3 cells were incubated in triplicate in 24-well plates with $100 \mathrm{nM}{ }^{3} \mathrm{H}-\mathrm{MT} 2$, in the presence or absence of 100 -fold excess MT2 or $4 \mathrm{nM}$ hrNGF for $30 \mathrm{~min}$ at $4^{\circ} \mathrm{C}$. After washing, cells were cultured at $37^{\circ} \mathrm{C}$ for $1 \mathrm{~h}$. Membrane bound radioactivity was eluted by $0.1 \mathrm{M}$ glycin buffer, $\mathrm{pH} 2$, and cells were lysed with $0.25 \mathrm{~N} \mathrm{NaOH}, 0.1 \%$ SDS. Internalized radioactivity was measured through liquid scintillation counting. $2 \times 10^{7}$ red blood cells were incubated as above with $100 \mathrm{nM}{ }^{3} \mathrm{H}-\mathrm{MT} 2$ at $37^{\circ} \mathrm{C}$ for 1 hour, washed and lysed with $\mathrm{NH}_{4} \mathrm{Cl}$.

\section{Conflict of Interest}

Antonio Guarna, Maria Gabriella Torcia, Enrico Garaci, and Federico Cozzolino declare conflict of interest, being inventors in the Patent covering the molecules described herein. All other authors declare no conflict of interest.

Acknowledgements. We wish to thank Dr V Granata and Professor A Zagari for their invaluable help in the binding studies, Dr N Cini and A Trabocchi for the synthesis of labeled MT2. This study was supported by grants from Consiglio Nazionale delle Ricerche (Progetto Strategico 'Neurobiotecnologie'), from Italian Ministry of Education (PRIN), from Italian Ministry of Health (Project 'Stromal, tumoral and antiangiogenic targeting'), from Progetto Fondazione Roma, from University of Firenze, and from CINMPIS (Consorzio Interuniversitario Nazionale 'Metodologie e Processi Innovativi di Sintesi').

\section{Author contributions}

$A G, M G T, E G, C M, P C$, and FC designed research; DS, GC, DC, CM, PR, FR, AMC, LB, and PB performed research; ATP contributed new analytic tools; EGO and ATP analyzed data; and FC wrote the paper.

1. Reichardt LF. Neurotrophin-regulated signalling pathways. Philos Trans R Soc Lond B Biol Sci 2006; 361: 1545-1564.

2. Caporali A, Emanueli C. Cardiovascular actions of neurotrophins. Physiol Rev 2009; 89: 279-308.

3. Barker PA. High affinity not in the vicinity? Neuron 2007; 53: 1-4.

4. Wehrman T, He X, Raab B, Dukipatti A, Blau H, Garcia KC. Structural and mechanistic insights into nerve growth factor interactions with the TrkA and p75 receptors. Neuron 2007; 53: 25-38.

5. Wiesmann $\mathrm{C}$, Ultsch MH, Bass SH, de Vos AM. Crystal structure of nerve growth factor in complex with the ligand-binding domain of the TrkA receptor. Nature 1999; 401: 184-188.

6. de Pablo Y, Perez-Garcia MJ, Georgieva MV, Sanchis D, Lindqvist N, Soler RM et al. Tyr-701 is a new regulatory site for neurotrophin receptor TrkA trafficking and function. J Neurochem 2008; 104: 124-139.

7. Calissano P, Amadoro G, Matrone C, Ciafre S, Marolda R, Corsetti V et al. Does the term 'trophic' actually mean anti-amyloidogenic? The case of NGF. Cell Death Differ 2010; 17: 1126-1133.

8. Chao MV, Rajagopal R, Lee FS. Neurotrophin signalling in health and disease. Clin Sci (Lond) 2006; 110: 167-173

9. Liskamp RM, Rijkers DT, Kruijtzer JA, Kemmink J. Peptides and proteins as a continuing exciting source of inspiration for peptidomimetics. Chembiochem 2011; 12: 1626-1653.

10. Guarna A, Guidi A, Machetti F, Menchi G, Occhiato EG, Scarpi D et al. Synthesis and reactivity of bicycles derived from tartaric acid and alpha-amino acids: a novel class of conformationally constrained dipeptide isosteres based upon enantiopure 3-Aza-6,8dioxabicyclo. J Org Chem 2000; 65: 4782.

11. Trabocchi A, Menchi G, Guarna F, Machetti F, Scarpi D, Guarna A. Design, synthesis, and applications of 3-aza-6,8-dioxabicyclo[3.2.1] octane-based scaffolds for peptidomimetic chemistry. Synlett 2006; 331-353.

12. Guarna A, Cozzolino F, Torcia M, Garaci E. Pharmaceutical compositions for the treatment of diseases related to neurotrophines. PCT/EP2003/006471(7625892). 1-12-2009. 18-6-2003; Ref type: Patent.

13. Abagyan R, Totrov M. Biased probability Monte Carlo conformational searches and electrostatic calculations for peptides and proteins. J Mol Biol 1994; 235: 983-1002.

14. Levi A, Ferri GL, Watson E, Possenti R, Salton SR. Processing, distribution, and function of VGF, a neuronal and endocrine peptide precursor. Cell Mol Neurobiol 2004; 24: 517-533.

15. Kim EK, Choi EJ. Pathological roles of MAPK signaling pathways in human diseases. Biochim Biophys Acta 2010; 1802: 396-405.

16. Torcia M, De Chiara G, Nencioni L, Ammendola S, Labardi D, Lucibello M et al. Nerve growth factor inhibits apoptosis in memory B lymphocytes via inactivation of p38 MAPK, prevention of $\mathrm{Bcl}-2$ phosphorylation, and cytochrome c release. J Biol Chem 2001; 276: 39027-39036. 
17. Rosini P, De Chiara G, Bonini P, Lucibello M, Marcocci ME, Garaci E et al. Nerve growth factor-dependent survival of CESS $B$ cell line is mediated by increased expression and decreased degradation of MAPK phosphatase 1. J Biol Chem 2004; 279: 14016-14023.

18. Vasudevan KM, Garraway LA. AKT signaling in physiology and disease. Curr Top Microbiol Immunol 2010; 347: 105-133.

19. Owens DM, Keyse SM. Differential regulation of MAP kinase signalling by dual-specificity protein phosphatases. Oncogene 2007; 26: 3203-3213.

20. Matrone C, Ciotti MT, Mercanti D, Marolda R, Calissano P. NGF and BDNF signaling control amyloidogenic route and Abeta production in hippocampal neurons. Proc Natl Acad Sci USA 2008; 105: 13139-13144.

21. Kenchappa RS, Zampieri N, Chao MV, Barker PA, Teng HK, Hempstead BL et al. Liganddependent cleavage of the P75 neurotrophin receptor is necessary for NRIF nuclear translocation and apoptosis in sympathetic neurons. Neuron 2006; 50: 219-232.

22. Lu B, Pang PT, Woo NH. The yin and yang of neurotrophin action. Nat Rev Neurosci 2005 6: $603-614$.

23. Ultsch MH, Wiesmann C, Simmons LC, Henrich J, Yang M, Reilly D et al. Crystal structures of the neurotrophin-binding domain of TrkA, TrkB and TrkC. J Mol Biol 1999; 290: 149-159.

24. Debeir T, Saragovi HU, Cuello AC. A nerve growth factor mimetic TrkA antagonist causes withdrawal of cortical cholinergic boutons in the adult rat. Proc Natl Acad Sci USA 1999; 96 4067-4072.

25. Beglova N, Maliartchouk S, Ekiel I, Zaccaro MC, Saragovi HU, Gehring K. Design and solution structure of functional peptide mimetics of nerve growth factor. J Med Chem 2000 43: 3530-3540.

26. Xie Y, Tisi MA, Yeo TT, Longo FM. Nerve growth factor (NGF) loop 4 dimeric mimetics activate ERK and AKT and promote NGF-like neurotrophic effects. J Biol Chem 2000; 275 29868-29874.

27. Jang SW, Okada M, Sayeed I, Xiao G, Stein D, Jin P et al. Gambogic amide, a selective agonist for TrkA receptor that possesses robust neurotrophic activity, prevents neuronal cell death. Proc Natl Acad Sci USA 2007; 104: 16329-16334.

28. Colangelo AM, Bianco MR, Vitagliano L, Cavaliere C, Cirillo G, De Gioia L et al. A new nerve growth factor-mimetic peptide active on neuropathic pain in rats. J Neurosci 2008; 28: 2698-2709.

29. Fletcher JM, Morton CJ, Zwar RA, Murray SS, O'Leary PD, Hughes RA. Design of a conformationally defined and proteolytically stable circular mimetic of brain-derived neurotrophic factor. J Biol Chem 2008; 283: 33375-33383.

30. Brahimi F, Malakhov A, Lee HB, Pattarawarapan M, Ivanisevic L, Burgess $\mathrm{K}$ et al. A peptidomimetic of NT-3 acts as a TrkC antagonist. Peptides 2009; 30: 1833-1839.
31. Massa SM, Yang T, Xie Y, Shi J, Bilgen M, Joyce JN et al. Small molecule BDNF mimetics activate TrkB signaling and prevent neuronal degeneration in rodents. J Clin Invest 2010; 120: $1774-1785$.

32. Liu J, Brahimi F, Saragovi HU, Burgess K. Bivalent diketopiperazine-based tropomysin receptor kinase C (TrkC) antagonists. J Med Chem 2010; 53: 5044-5048.

33. Matrone C, Marolda R, Ciafre S, Ciotti MT, Mercanti D, Calissano P. Tyrosine kinase nerve growth factor receptor switches from prosurvival to proapoptotic activity via Abeta-mediated phosphorylation. Proc Natl Acad Sci USA 2009; 106: 11358-11363.

34. Semenova MM, Maki-Hokkonen AM, Cao J, Komarovski V, Forsberg KM, Koistinaho $\mathrm{M}$ et al. Rho mediates calcium-dependent activation of p38alpha and subsequent excitotoxic cell death. Nat Neurosci 2007; 10: 436-443.

35. Filomeni G, Cardaci S, Costa Ferreira AM, Rotilio G, Ciriolo MR. Metabolic oxidative stress elicited by the copper(II) complex [Cu(isaepy)2] triggers apoptosis in SH-SY5Y cells through the induction of the AMP-activated protein kinase/p38MAPK/p53 signalling axis: evidence for a combined use with 3-bromopyruvate in neuroblastoma treatment. Biochem J 2011; 437: 443-453.

36. Horbinski C, Chu CT. Kinase signaling cascades in the mitochondrion: a matter of life or death. Free Radic Biol Med 2005; 38: 2-11.

37. Kaiser RA, Bueno OF, Lips DJ, Doevendans PA, Jones F, Kimball TF et al. Targeted inhibition of p38 mitogen-activated protein kinase antagonizes cardiac injury and cell death following ischemia-reperfusion in vivo. J Biol Chem 2004; 279: 15524-15530.

38. Meloni M, Caporali A, Graiani G, Lagrasta C, Katare R, Van Linthout S et al. Nerve growth factor promotes cardiac repair following myocardial infarction. Circ Res 2010; 106 : $1275-1284$.

39. Matrone C, Barbagallo AP, La Rosa LR, Florenzano F, Ciotti MT, Mercanti D et al. APP is phosphorylated by TrkA and regulates NGF/TrkA signaling. J Neurosci 2011; 31: 11756-11761.

40. An J, Totrov M, Abagyan R. Pocketome via comprehensive identification and classification of ligand binding envelopes. Mol Cell Proteomics 2005; 4: 752-761.

Cell Death and Disease is an open-access journal published by Nature Publishing Group. This work is licensed under the Creative Commons Attribution-NonCommercial-No Derivative Works 3.0 Unported License. To view a copy of this license, visit http://creativecommons.org/licenses/by-nc-nd/3.0/

Supplementary Information accompanies the paper on Cell Death and Disease website (http://www.nature.com/cddis) 